\title{
The Antitumor Immunity and Tumor Responses of Chemotherapy with or without DC-CIK for Non-Small-Cell Lung Cancer in China: A Meta-Analysis of 28 Randomized Controlled Trials
}

\author{
Zheng Xiao $\mathbb{D}^{1,2}$ Cheng-qiong Wang, ${ }^{1,2}$ Ming-hua Zhou, ${ }^{1}$ Na-na Li, ${ }^{1,2}$ Yong-ping Sun, \\ Yu-zhi Wang, ${ }^{4}$ Shi-yu Liu, ${ }^{1}$ Hong-song Yu $\mathbb{D},{ }^{5}$ Cheng-wen Li, ${ }^{4}$ Xian-tao Zeng $\left(\mathbb{D},{ }^{6}\right.$ \\ Ling Chen, ${ }^{1,2}$ Xin-sheng Yao $\mathbb{D}^{5},{ }^{5}$ and Ji-hong Feng $\mathbb{D}^{7}$ \\ ${ }^{1}$ Evidence-Based Medicine Center, MOE Virtual Research Center of Evidence-Based Medicine at Zunyi Medical College, \\ Affiliated Hospital of Zunyi Medical College, Zunyi, 563000 Guizhou, China \\ ${ }^{2}$ Department of Respiratory Medicine (Center for Evidence-Based and Translational Medicine of Major Infectious Diseases), \\ Affiliated Hospital of Zunyi Medical College, Zunyi, 563000 Guizhou, China \\ ${ }^{3}$ Teaching and Research Group of Evidence-based Medicine, Zhuhai Campus of Zunyi Medical College, Zhuhai, \\ 519000 Guangdong, China \\ ${ }^{4}$ Department of immunology, Southwest Medical University, Luzhou, 646000 Sichuan, China \\ ${ }^{5}$ Department of Immunology, Special Key Laboratory of Gene Detection \& Therapy of Guizhou Province, Zunyi Medical College, \\ Zunyi, 563000 Guizhou, China \\ ${ }^{6}$ Center for Evidence-Based and Translational Medicine, Zhongnan Hospital of Wuhan University, Wuhan, 430071 Hubei, China \\ ${ }^{7}$ Department of Oncology, Affiliated Hospital of Zunyi Medical College, Zunyi, 563000 Guizhou, China
}

Correspondence should be addressed to Zheng Xiao; zy426f@163.com and Ji-hong Feng; jh_f@163.com

Received 5 July 2018; Revised 4 September 2018; Accepted 3 October 2018; Published 13 December 2018

Guest Editor: Lei Zhao

Copyright (C) 2018 Zheng Xiao et al. This is an open access article distributed under the Creative Commons Attribution License, which permits unrestricted use, distribution, and reproduction in any medium, provided the original work is properly cited.

Objective. DC-CIK therapy included DC-CIK cells and Ag-DC-CIK cells. To further confirm whether DC-CIK reconstructs the antitumor immunity and improves the tumor responses and reveals its optimal usage and combination with chemotherapy, we systematically reevaluated all the related studies. Materials and Methods. All studies about DC-CIK plus chemotherapy for NSCLC were collected from the published and ongoing database as CBM, CNKI, VIP, Wanfang, ISI, Embase, MEDLINE, CENTRAL, WHO-ICTRP, Chi-CTR, and US clinical trials (established on June 2017). We evaluated their methodological bias risk according to the Cochrane evaluation handbook of RCTs (5.1.0), extracted data following the predesigned data extraction form, and synthesized the data using meta-analysis. Results. We included 28 RCTs (phase IV) with 2242 patients, but most trials had unclear bias risk. The SMD and $95 \% \mathrm{CI}$ of meta-analysis for $\mathrm{CD}^{+}{ }^{+} \mathrm{T}$ cells, $\mathrm{CD}^{+} \mathrm{CD}^{+} \mathrm{T}$ cells, $\mathrm{CD}^{+} \mathrm{CD}^{+} \mathrm{T}^{-}$cells, $\mathrm{CD}^{+} /$ $\mathrm{CD}^{+} \mathrm{T}$ cell ratio, CIK cells, NK cells, and Treg cells were as follows: 1.85 (1.39 to 2.31), 0.87 (0.65 to 1.10$), 1.04$ (0.58 to 1.50 ), 0.75 (0.27 to 1.22 ), 3.87 (2.48 to 5.25$), 1.51$ (0.99 to 2.03 ), and $-2.31(-3.84$ to -0.79$)$. The RR and $95 \%$ CI of metaanalysis for ORR and DCR were as follows: 1.38 (1.24 to 1.54) and 1.27 (1.20 to 1.34). All differences were statistically significant between DC-CIK plus chemotherapy and chemotherapy alone. Subgroup analysis showed that only DC-CIK cells could increase the $\mathrm{CD}^{+}{ }^{+} \mathrm{T}$ cells, $\mathrm{CD}^{+}{ }^{+} \mathrm{CD} 4^{+} \mathrm{T}$ cells, $\mathrm{CD} 3^{+} \mathrm{CD} 8^{+} \mathrm{T}$ cells, and $\mathrm{CD} 4^{+} / \mathrm{CD} 8^{+} \mathrm{T}$ cell ratio. In treatment with one cycle or two cycles and combination with NP or GP, DC-CIK could increase the CD4 ${ }^{+} / \mathrm{CD}^{+} \mathrm{T}$ cell ratio. All results had good stability. Conclusions. DC-CIK therapy can simultaneously improve the antitumor immunity and tumor responses. DC-CIK therapy, especially DC-CIK cells, can improve antitumor immunity through increasing the T lymphocyte subsets, CIK cell, and NK cells in peripheral blood. The one cycle to two cycles may be optimal cycle, and the NP or GP may be optimal combination. 


\section{Introduction}

Non-small-cell lung cancer (NSCLC) remains the leading cause of cancer-related death worldwide [1-3]. Most clinically diagnosed patients undergo advanced local invasion and distant metastasis and therefore miss the opportunity of operative eradication. Hence, they are forced to accept the systemic chemotherapy. However, systemic chemotherapy damages host's immune function and weakens the antitumor immunity which result in poor tumor responses, survival, and quality of life (QOL) [4-6]. Therefore, how to repair and reconstruct antitumor immunity is the key to successful treatment. Dendritic cells (DC) are the most powerful antigen-presenting cells so far and play an important regulating role in host's immune response. DCs capture and process the tumor-associated antigens and then activate the antigenspecific cytotoxic $\mathrm{T}$ lymphocytes and induce the antitumor immune responses. Especially, dendritic cells pulsed with tumor-associated antigen(s) (Ag-DC cells) have stronger activity in mediating the antitumor immune responses than DC cells alone in vitro and in vivo [7-9]. Cytokine-induced killer cells $\left(\mathrm{CD}^{+}{ }^{+} \mathrm{CD} 56^{+}\right.$cells, CIK cells) were first described by Schmidt-Wolf et al. in 1991 [10], who also performed the first clinical trial with CIK cells in the treatment of cancer patients in 1999 [11]. CIK cells are nonmajor histocompatibility complex-restricted natural killer $\mathrm{T}$ lymphocytes and have stronger cytolytic activities against tumor than lymphokine-activated killer cells [12-16]. Coculture of DCs or Ag-DC cells and CIK cells results in considerable increase of antitumor immunity and shows stronger cytotoxic activity than single CIK treatment [17-19]. Therefore, DC cells or Ag-DC cells cocultured with CIK cells and formed DC-CIK therapy which are important cellular immunotherapy including the DC-CIK cells and Ag-DC-CIK cells.

DC-CIK therapy has been widely studied and applied in many kinds of malignant tumors [20-24]. Whether DCCIK therapy repair and reconstruct antitumor immunity is the primary question to successful treatment. Antitumor immunity is expressed by indicators such as T lymphocyte subsets, natural killer cells (NK cells), and Th1 cytokines which are of great value for early judgement of clinical efficacy in DC-CIK treatment. Previous studies $[25,26]$ reported that CIK/DC-CIK therapy could significantly increase the proportion of $\mathrm{CD}^{+} \mathrm{T}$ cells, $\mathrm{CD}^{+} \mathrm{CD}^{+} \mathrm{T}$ cells, and the ratio of $\mathrm{CD}^{+} / \mathrm{CD}^{+} \mathrm{T}$ cells and improve the tumor responses for NSCLC. However, this meta-analysis included the CIK and DC-CIK therapy, not focused on DC-CIK therapy. Lan et al. [27] further reported that the immunotherapy of DCCIK cells significantly increased the proportion of $\mathrm{CD}^{+} \mathrm{T}$ cells, $\mathrm{CD}^{+}{ }^{+} \mathrm{CD} 4^{+} \mathrm{T}$ cells, and the ratio of $\mathrm{CD} 4^{+} / \mathrm{CD}^{+} \mathrm{T}$ cells and decreased the $\mathrm{CD}^{+} \mathrm{CD}^{+} \mathrm{T}$ cells in malignant tumors. This meta-analysis involved the rectal cancer, colorectal cancer, breast cancer, and NSCLC, not focused on NSCLC. Can DC-CIK therapy repair and reconstruct the antitumor immunity for NSCLC? In 2015, Hu et al. [28] reported that compared with chemotherapy, DC-CIK therapy could significantly increase the $\mathrm{CD}^{+} \mathrm{T}$ cells, $\mathrm{CD}^{+} \mathrm{CD}^{+} \mathrm{T}$ cells, and $\mathrm{CD}^{+} / \mathrm{CD}^{+} \mathrm{T}$ cell ratio in NSCLC. The proportions of $\mathrm{CD}^{+} \mathrm{CD}^{+} \mathrm{T}$ cells were not statistically different between the two groups. However, Sun et al. [29] further reported that compared with platinum chemotherapy, DC-CIK therapy could significantly increase the proportions of $\mathrm{CD}^{+} \mathrm{T}$ cells, $\mathrm{CD}^{+} \mathrm{CD}^{+} \mathrm{T}$ cells, and the ratio of $\mathrm{CD}^{+} / \mathrm{CD}^{+} \mathrm{T}$ cells in NSCLC. In 2016, Zhou et al. [30] reported that compared with chemotherapy, DC-CIK therapy could only increase the proportions of $\mathrm{CD}^{+} \mathrm{T}$ cells, natural killer cells (NK cells), and CIK cells. But the proportions of $\mathrm{CD}^{+}$ $\mathrm{CD}^{+}{ }^{+} \mathrm{T}$ cells, $\mathrm{CD}^{+}{ }^{+} \mathrm{CD} 8^{+} \mathrm{T}$ cells, and $\mathrm{CD} 25^{+} \mathrm{CD} 4^{+} \mathrm{T}$ cells (Treg cells) were not statistically different between the two groups. The results indicated that DC-CIK therapy might repair and reconstruct antitumor immunity for NSCLC through upregulating the T lymphocyte subsets and NK cells in peripheral blood. And there was controversy whether DC-CIK therapy improved the $\mathrm{CD}^{+} \mathrm{CD}^{+} \mathrm{T}$ cells. What usage and combinations with chemotherapy could improve the antitumor immunity remains unclear. In addition, DCCIK cells and Ag-DC-CIK cells are different from each other. Therefore, current evidences [28-30] fail to answer whether DC-CIK cells or Ag-DC-CIK cells improve the antitumor immunity.

In clinical practice, there was outstanding diversity in different DC-CIK therapy and their usages and combinations with chemotherapy. All these might show different effects on clinical efficacy and then might be important factors in hindering the success of individualized immunotherapy. Up to now, many studies [31-33] had been published. Therefore, to further confirm whether DC-CIK therapy repairs and reconstructs the antitumor immunity, reveals its optimal usage and combination with chemotherapy, and provides the optimal evidence for individualized immunotherapy, we systematically reevaluated all the related studies.

\section{Materials and Methods}

This study was implemented according to the Preferred Reporting Items for Systematic Reviews and Meta-Analyses guidelines (PRISMA guidelines). Ethical approval was not required, as all materials of this study were published or unpublished studies.

2.1. Search Strategy. Two reviewers (Cheng-qiong Wang and Ming-hua Zhou) independently retrieved all the published studies in Chinese and English databases as Chinese Biomedical Literature (CBM), Chinese Scientific Journals Full-Text Database (CNKI), China National Knowledge Infrastructure Database (VIP) and Wanfang, Web of Science (ISI), Embase, MEDLINE, and Cochrane Central Register of Controlled Trials (CENTRAL) and further retrieved all the ongoing studies in WHO International Clinical Trials Registry Platform (WHO-ICTRP), Chinese Clinical Trial Registry (Chi-CTR), and US clinical trials (established on June 2017). All retrievals were implemented by using the Chinese and English MeSH and free word as "Dendritic cell and Cytokine Induced Killer Cells", "Dendritic cells and Cytokine-Induced Killer Cell", "Dendritic cell and Cytokine-Induced Killer Cell", "Dendritic cells and Cytokine Induced Killer Cells", "DCs CIK", "DC CIK", "DC Cik", "DCs Cik", "Lung Neoplasms"[Mesh], "Non-Small-Cell Lung” [Mesh], "Non small 
cell lung cancer", "Non small cell lung cancers", "Carcinoma, non-small cell lung cancer", "Non-small cell lung cancers", "NSCLC", "Pulmonary Neoplasms", "Lung Neoplasm", "Pulmonary Neoplasm", "Lung Cancer", "Lung Cancers", "Pulmonary Cancer", "Pulmonary Cancers", "Lung carcinoma" and "Pulmonary carcinoma". Finally, we identified and evaluated all related systematic reviews (SRs) or meta-analysis and then selected all the studies meeting the inclusion criteria from their references.

2.2. Inclusion and Exclusion Criteria. Included studies must meet the following criteria. The disease was diagnosed as NSCLC using histopathological and cytological diagnostic criteria and TNM staging system [34]. There were no severe liver or kidney dysfunctions in any of the patients. Before being included, all patients did not receive the surgery, radiotherapy, CIK cells alone, traditional Chinese medicines, monoclonal antibody, or other cell therapies. DC-CIK therapy included DC-CIK cells and Ag-DC-CIK cells. The experimental groups were DC-CIK plus chemotherapy, and the control groups were chemotherapy alone without restrictions on the types. Main outcomes were antitumor immunity, and secondary outcomes were tumor responses. All studies were randomized controlled trials (RCTs). No restrictions were set on the follow-ups and types of research institutes.

Excluded studies must meet the following criteria: duplicates; patent, generic, abstracts, and reviews without specific data; in vitro or animal studies; studies about other tumors or nursing; studies with CIK cells or DC-CIK alone; studies with DC-CIK plus radiotherapy, Chinese herbs, targeted therapy, surgery, or other cytotherapy; studies with DCCIK in two groups; nonrandomized controlled studies; unrelated SR or meta-analysis; studies without data of peripheral blood lymphocytes; and studies without being included in CBM.

2.3. Study Selection. Two reviewers (Shi-yu Liu and Na-na Li) independently selected the qualified studies in accordance with the predesigned inclusion and exclusion criteria. Any disagreements about selection were eliminated through discussing between themselves or with Zheng Xiao.

2.4. Bias Risk Assessment. Two reviewers (Yu-zhi Wang and Yong-ping Sun) evaluated the bias risk in accordance with the Cochrane evaluation handbook of RCTs (5.1.0) [35]. The bias parameters were the random sequence generation (selection bias), the allocation concealment (selection bias), the blinding of patients and researchers (performance bias), the blinding of outcome assessors (detection bias), the follow-up (attrition bias), the selective reporting (reporting bias), and the other bias (not comparable baseline). We judged each item on three levels " "yes" for a low risk of bias, "no" for a high risk of bias, and "unclear"). Then, we assessed the studies and categorized them into three levels: low risk of bias (low risk of bias for all key domains), high risk of bias (high risk of bias for one or more key domains), and unclear (unclear risk of bias for all key domains). Any disagreements of judgment about "high risk, low risk, or unclear" were resolved through discussing between themselves or with the third reviewer (Zheng Xiao).

2.5. Outcome Measures. We evaluated antitumor immunity using the peripheral blood lymphocytes that included $\mathrm{T}$ lymphocyte subsets and natural killer cells (NK cells). T lymphocyte subsets were measured by using the proportions of $\mathrm{CD}^{+}{ }^{+} \mathrm{T}$ cells, $\mathrm{CD}^{+}{ }^{+} \mathrm{CD}^{+} \mathrm{T}$ cells, $\mathrm{CD}^{+}{ }^{+} \mathrm{CD}^{+} \mathrm{T}$ cells, $\mathrm{CIK}$ cells $\left(\mathrm{CD}^{+}{ }^{+} \mathrm{CD}^{+} 6^{+}\right.$cells), and regulatory $\mathrm{T}$ cells $\left(\mathrm{CD} 25^{+}\right.$ $\mathrm{CD}^{+} \mathrm{T}$ cells, Treg cells) and the ratio of $\mathrm{CD} 4^{+} / \mathrm{CD}^{+} \mathrm{T}$ cells. All indicators were detected by using the flow cytometry (FCM) or other methods after treatment. Tumor responses were measured by using the objective response rate (ORR) and disease control rate (DCR). According to the World Health Organization (WHO) guidelines for solid tumor responses [36] or response evaluation criteria in solid tumors (RECIST) [37], indicators were complete response (CR), partial response (PR), no change (NC), progressive disease (PD), ORR being equal to CR plus PR, and DCR being equal to CR plus PR and NC.

2.6. Data Extraction. Two reviewers (Yu-zhi Wang and Hong-song $\mathrm{Yu}$ ) independently extracted all the data in accordance with predesigned data extraction form, and all the data included the publishing time and author, the demographic characteristics, the sample sizes of experimental and control groups, DC-CIK types and usages, combinations with chemotherapy, evaluation methods and times, and main outcomes as the proportions of $\mathrm{CD}^{+} \mathrm{T}$ cells, $\mathrm{CD}^{+} \mathrm{CD}^{+} \mathrm{T}$ cells, $\mathrm{CD}^{+} \mathrm{CD}^{+} \mathrm{T}$ cells, CIK cells, regulatory $\mathrm{T}$ cells (Treg cells), and NK cells, and the ratio of $\mathrm{CD}^{+} / \mathrm{CD}^{+} \mathrm{T}$ cells, secondary outcomes as ORR and DCR.

2.7. Statistical Analysis. Two reviewers (Cheng-qiong Wang and Ming-hua Zhou) implemented the meta-analysis using the Review Manager 5.3 (The Cochrane Collaboration, Oxford, UK). The relative risk (RR) and standardized mean difference (SMD) and 95\% confidence intervals (CI) were used to describe the dichotomous and continuous variables, respectively. Statistical heterogeneity across trials was assessed by Pearson's chi-square test and $I^{2}$ test [38]. When substantial heterogeneity $\left(P<0.1, I^{2}>50 \%\right)$ was rejected, the fixed-effects model (FEM) was used to calculate the summary RR and the $95 \%$ CI. Otherwise, the data was calculated through a random-effects model (REM). To show the clinical heterogeneity and its influence on $\mathrm{T}$ lymphocyte subsets and further reveal the optimal usage and combination with chemotherapy of DC-CIK therapy, subgroup analysis was performed according to the DC-CIK types, treatment cycles, and different chemotherapy. Publication bias was evaluated by using the funnel plots when there were more than 10 included trials. Sensitivity analysis was performed through excluding the poor trials or over- or underestimated trials [39]. The trial was identified as poor trial that had at least one domain considered as high risk of bias. The trial was identified as over- or under-estimated trial, when results had statistical difference and positive effects on publication bias or heterogeneity. 


\section{Results}

3.1. Search Results. We retrieved 1190 published records and 99 ongoing trials through using the search strategies (Figure 1). We primarily excluded the duplicates and we included 650 records and 55 ongoing trials. We screened the abstracts and rejected the unrelated records et. al. and included 92 full-texts, 12 SRs [25-30, 40-45], and 4 ongoing trials. We further evaluated the full-text and SRs, rejected the unqualified studies, incomplete trials, and poor studies without being included in CBM, and we included 28 RCTs [31-33, 42, 46-69] from database and 12 RCTs [46-57] from SR or meta-analysis. Finally, we excluded the duplicates [46-57] and included 28 RCTs [31-33, 42, 46-69] for the meta-analysis.

3.2. Characteristics of Included Studies. In this meta-analysis, we included 28 RCTs [31-33, 42, 46-69] with 2242 NSCLC patients from China (Table 1). All patients were middle to late stage NSCLC without undergoing surgery. The males and females were 1256 cases and 792 cases with age range 18 to 83 years. DC-CIK plus chemotherapy and chemotherapy alone were 1127 cases and 1115 cases, respectively. In experimental groups, the patients underwent the DC-CIK cells in 22 RCTs $[31,33,42,46-50,52,54,55,57-65,67$, 68] and Ag-DC-CIK cells in 6 RCTs [32, 51, 53, 56, 66, 69], respectively. DC-CIK cells were mainly used by intravenous injection with $1-10 \times 10^{9} /$ times, 2-6 times/cycle, and 1-6 cycles after chemotherapy. The control groups underwent chemotherapy alone as vinorelbine and cisplatin (NP), docetaxel and cisplatin (DP), paclitaxel and cisplatin (TP), gemcitabine and cisplatin (GP), et al. All the trials evaluated antitumor immunity using the peripheral blood lymphocytes after treatment. The cells were mainly detected by using the flow cytometry (FCM). Twenty-four trials [31-33, 42, 46$52,54-61,63,65,66,68,69]$ with 1949 cases reported the tumor responses according to the WHO guidelines for solid tumor responses [36] or RECIST [37], respectively.

3.3. Methodological Bias Risk. In 28 trials, only 11 trials reported the random sequence generation using the random number table [32, 33, 49, 51, 58-61, 63, 68, 69]. One trial [60] was allocation open, other trials did not provide the detailed information about the allocation concealment. None of the trials provided the detailed information about the blindings. One trial [66] had loss to follow-up. Two trials $[48,66]$ failed to completely report the tumor responses. Except for three trials $[46,48,49]$, others were baseline comparability. Methodological bias risk was presented in Figure 2.

3.4. Peripheral Blood T Lymphocyte Subsets. In 28 RCTs, 23 trials with 1888 cases reported the $\mathrm{CD}^{+} \mathrm{T}$ cells (Figure 3 ). Pearson's chi-square test and $I^{2}$ test showed that there was statistical heterogeneity among the trials $\left(\mathrm{Chi}^{2}=385.54\right.$, $\left.P<0.00001, I^{2}=94 \%\right)$. Therefore, the data was calculated by using a REM. The meta-analysis result showed that the proportions of $\mathrm{CD}^{+} \mathrm{T}$ cells had statistical difference between DC-CIK plus chemotherapy and chemotherapy alone $[\mathrm{SMD}=1.85,95 \% \mathrm{CI}(1.39$ to 2.31$), P<0.00001]$.
Twenty-three trials with 1889 cases reported the $\mathrm{CD}^{+}$ $\mathrm{CD}^{+} \mathrm{T}$ cells (Figure 4). There was statistical heterogeneity among the trials $\left(\mathrm{Chi}^{2}=115.80, P<0.00001, I^{2}=81 \%\right)$. Therefore, the data was calculated by using a REM. The meta-analysis result showed that the $\mathrm{CD}^{+} \mathrm{CD}^{+} \mathrm{T}$ cells had statistical difference between the two groups $[\mathrm{SMD}=0.87$, 95\% CI (0.65 to 1.10$), P<0.00001]$.

Twenty-six trials with 2066 cases reported the $\mathrm{CD}^{+}$ $\mathrm{CD}^{+} \mathrm{T}$ cells (Figure 5). There was statistical heterogeneity among the trials $\left(\mathrm{Chi}^{2}=556.12, P<0.00001, I^{2}=96 \%\right)$. Therefore, the data was calculated by using a REM. The meta-analysis result showed that the $\mathrm{CD} 3^{+} \mathrm{CD}^{+} \mathrm{T}$ cells had statistical difference between the two groups $[\mathrm{SMD}=1.04$, 95\% CI (0.58 to 1.50$), P<0.00001]$.

Fifteen trials with 1068 cases reported the $\mathrm{CD} 4^{+} / \mathrm{CD}^{+} \mathrm{T}$ cell ratio (Figure 6). There was statistical heterogeneity among the trials $\left(\mathrm{Chi}^{2}=165.60, P<0.00001, I^{2}=92 \%\right)$. Therefore, the data was calculated by using a REM. The meta-analysis result showed that the ratio of $\mathrm{CD} 4^{+} / \mathrm{CD} 8^{+}$ $\mathrm{T}$ cells had statistical difference between the two groups $[\mathrm{SMD}=0.75,95 \% \mathrm{CI}(0.27$ to 1.22$), P=0.002$ ].

Only 7 trials with 519 cases reported the CIK cells (Figure 7(a)). There was statistical heterogeneity among the trials $\left(\mathrm{Chi}^{2}=158.52, P<0.00001, I^{2}=96 \%\right)$. Therefore, the data was calculated by using a REM. The meta-analysis result showed that the CIK cells had statistical difference between the two groups [SMD $=3.87,95 \% \mathrm{CI}(2.48$ to 5.25$)$, $P<0.00001]$.

Only 6 trials with 475 cases reported the $\mathrm{CD} 25^{+} \mathrm{CD} 4^{+} \mathrm{T}$ cells (Treg cells) (Figure 7(b)). There was statistical heterogeneity among the trials $\left(\mathrm{Chi}^{2}=204.54, P<0.00001, I^{2}=98 \%\right)$. Therefore, the data was calculated by using a REM. The meta-analysis result showed that the Treg cells had statistical difference between the two groups [SMD $=-2.31,95 \% \mathrm{CI}$ (-3.84 to -0.79$), P=0.003$ ].

3.5. Natural Killer Cells (NK Cells). In 28 trials, 15 trials with 1374 cases reported the NK cells (Figure 8). There was statistical heterogeneity among the trials $\left(\mathrm{Chi}^{2}=255.43\right.$, $\left.P<0.00001, I^{2}=95 \%\right)$. Therefore, the data was calculated by a REM. The meta-analysis result showed that the NK cells had statistical difference between the two groups $[\mathrm{SMD}=1.51,95 \% \mathrm{CI}(0.99$ to 2.03$), P<0.00001]$.

3.6. Tumor Responses. According to the guidelines for solid tumor responses, tumor responses were evaluated by using the ORR and DCR. In 28 RCTs, 23 trials with 1829 cases reported the ORR. There was no statistical heterogeneity among the trials $\left(\mathrm{Chi}^{2}=8.07, P=1.00, I^{2}=0 \%\right)$. Therefore, the data were calculated by using a FEM. Compared with chemotherapy alone, the meta-analysis result showed that DC-CIK plus chemotherapy increased the ORR. The difference was statistically significant between DC-CIK plus chemotherapy and chemotherapy alone $(R R=1.38,95 \%$ CI 1.24 to $1.54, P<0.00001$, Figure 9 (a)). Twenty-two trials with 1761 cases reported the DCR. There was minimal heterogeneity among the trials $\left(\mathrm{Chi}^{2}=24.65, P=0.26\right.$, $\left.I^{2}=15 \%\right)$. Therefore, the data were calculated by using a FEM. The meta-analysis result showed that DC-CIK plus 


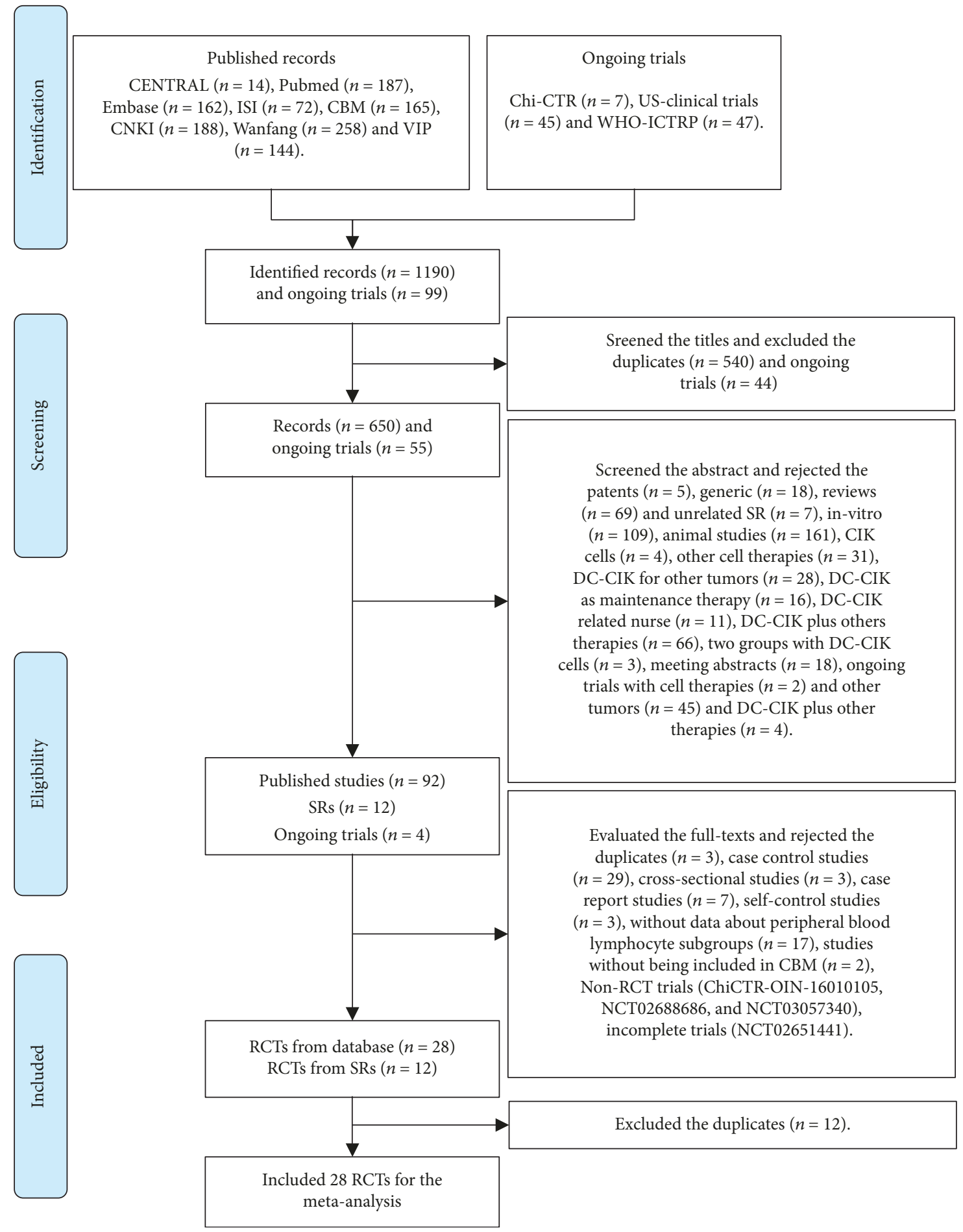

Figure 1: Articles retrieved and assessed for eligibility.

chemotherapy increased the DCR, and the difference was statistically significant between the two groups $(R R=1.27$, 95\% CI 1.20 to $1.34, P<0.00001$, Figure 9(b)).

3.7. Subgroup Analysis. To reveal the clinical heterogeneity and its influence on $\mathrm{CD}^{+} \mathrm{T}$ cells, $\mathrm{CD}^{+} \mathrm{CD}^{+} \mathrm{T}$ cells, $\mathrm{CD}^{+} \mathrm{CD}^{+} \mathrm{T}$ cells, and $\mathrm{CD} 4^{+} / \mathrm{CD}^{+} \mathrm{T}$ cell ratio, subgroup analyses were performed according to the DC-CIK types, treatment cycles, and combinations with chemotherapy. Firstly, subgroup analyses showed that DC-CIK cells could increase the proportions of $\mathrm{CD}^{+} \mathrm{T}$ cells, $\mathrm{CD}^{+}{ }^{+} \mathrm{CD} 4^{+} \mathrm{T}$ cells, $\mathrm{CD}^{+}{ }^{+} \mathrm{CD} 8^{+} \mathrm{T}$ cells, and the ratio of $\mathrm{CD} 4^{+} / \mathrm{CD}^{+} \mathrm{T}$ cells, but Ag-DC-CIK cells could only increase the $\mathrm{CD}^{+}{ }^{+} \mathrm{T}$ cells and $\mathrm{CD}^{+} \mathrm{CD}^{+} \mathrm{T}$ cells (Table 2, Figure S1-4). Secondly, in treatment with one cycle or three cycles, DC-CIK therapy could increase the $\mathrm{CD}^{+} \mathrm{T}$ cells, $\mathrm{CD}^{+}{ }^{+} \mathrm{CD}^{+}{ }^{+} \mathrm{T}$ cells, and $\mathrm{CD}^{+}$ 
TABLE 1: Characteristics of included studies.

\begin{tabular}{|c|c|c|c|c|c|c|c|c|c|c|c|}
\hline \multirow{2}{*}{$\begin{array}{l}\text { First } \\
\text { author, } \\
\text { year }\end{array}$} & \multicolumn{4}{|c|}{ NSCLC } & \multicolumn{3}{|c|}{ Interventions } & \multirow[b]{2}{*}{ Criteria } & \multirow[b]{2}{*}{ Detecting } & \multirow[b]{2}{*}{ Time } & \multirow[b]{2}{*}{$\mathrm{O}$} \\
\hline & Stage & $\mathrm{E} / \mathrm{C}$ & $\mathrm{M} / \mathrm{F}$ & Years & Cells & Usage & $\mathrm{C}$ & & & & \\
\hline $\begin{array}{l}\mathrm{Xu}, \mathrm{Y.} \\
2010[46]\end{array}$ & III-IV & $38 / 40$ & $57 / 21$ & $47-75$ & $\begin{array}{l}\text { DC-CIK } \\
\text { cells }\end{array}$ & $\begin{array}{c}\text { CIK: } 1.3-1.6^{*} 10^{9} / \\
\text { time (IV); DC (IC); } \\
8-10 \text { times/cycle, } 2 \\
\text { cycles }\end{array}$ & NP & RECIST & FCM & $4 w$ & $\mathrm{O} 1, \mathrm{O} 2$ \\
\hline $\begin{array}{l}\text { Sheng, C., } \\
2011 \text { [47] }\end{array}$ & III-IV & $32 / 33$ & $37 / 28$ & $35-65$ & $\begin{array}{l}\text { DC-CIK } \\
\text { cells }\end{array}$ & $\begin{array}{l}5^{*} 10^{9} / \text { time, } 4 \text { times/ } \\
\text { cycle, } 2 \text { cycles (IV) }\end{array}$ & NP & WHO & FCM & $2 \mathrm{w}$ & $\mathrm{O} 1, \mathrm{O} 2$ \\
\hline $\begin{array}{l}\text { Yuan, J., } \\
2011[48]\end{array}$ & Advanced & $34 / 34$ & $42 / 26$ & Unclear & $\begin{array}{l}\text { DC-CIK } \\
\text { cells }\end{array}$ & $\begin{array}{l}\text { Unclear, } 4 \text { times/ } \\
\text { cycle, } 1 \text { cycle (IV) }\end{array}$ & Chemo* & WHO & Unclear & $4 w$ & $\mathrm{O} 1, \mathrm{O} 2$ \\
\hline $\begin{array}{l}\text { He, J., } \\
2012[49]\end{array}$ & III-IV & $31 / 31$ & Unclear & $33-75$ & $\begin{array}{l}\text { DC-CIK } \\
\text { cells }\end{array}$ & $\begin{array}{l}\text { Unclear, } 2 \text { times/ } \\
\text { cycle, } 2 \text { cycles (IV) }\end{array}$ & NP & WHO & Unclear & After & $\mathrm{O} 1, \mathrm{O} 2$ \\
\hline $\begin{array}{l}\text { Peng, D., } \\
2012[50]\end{array}$ & IIIa-IV & $24 / 23$ & $29 / 18$ & $65-79$ & $\begin{array}{l}\text { DC-CIK } \\
\text { cells }\end{array}$ & $\begin{array}{l}\text { DC: } 1-10^{*} 10^{9} / \text { time, } \\
\text { CIK: } 1-20^{* 10} 11 / \text { time, } \\
2-3 \text { times, } 1 \text { cycle (IV) }\end{array}$ & ALIMTA & RECIST & FCM & After & $\mathrm{O} 1, \mathrm{O} 2$ \\
\hline $\begin{array}{l}\text { Shi, S. B., } \\
2012[51]\end{array}$ & IIIb-IV & $30 / 30$ & $35 / 25$ & $40-77$ & $\begin{array}{l}\text { Ag-DC-CIK } \\
\text { cells }\end{array}$ & $\begin{array}{l}\text { DC: -, } 4 \text { times (SI); } \\
\text { CIK: -, } 5 \text { times, } \\
1 \text { cycle (IV) }\end{array}$ & DP, GP & Unclear & FCM & After & $\mathrm{O} 1, \mathrm{O} 2$ \\
\hline $\begin{array}{l}\text { Zhao, L., } \\
\text { 2013[52] }\end{array}$ & IIIb-IV & $36 / 36$ & Unclear & $60-80$ & $\begin{array}{l}\text { DC-CIK } \\
\text { cells }\end{array}$ & $\begin{array}{l}\text { Unclear, } 3 \text { times/ } \\
\text { cycle, } 2 \text { cycles (IV) }\end{array}$ & DP & RECIST & FCM & After & $\mathrm{O} 1, \mathrm{O} 2$ \\
\hline $\begin{array}{l}\text { Zhu, Y., } \\
2013 \text { [53] }\end{array}$ & IIIb-IV & $30 / 31$ & $32 / 29$ & $44-72$ & $\begin{array}{l}\text { Ag-DC-CIK } \\
\text { cells }\end{array}$ & $\begin{array}{l}\text { Unclear, } 4 \text { times/ } \\
\text { cycle, 1cycle (IV) }\end{array}$ & $\mathrm{TP}$ & No & FCM & After & O1 \\
\hline $\begin{array}{l}\text { Han, W., } \\
2014[54]\end{array}$ & Advanced & $42 / 23$ & $45 / 20$ & Unclear & $\begin{array}{l}\text { DC-CIK } \\
\text { cells }\end{array}$ & $\begin{array}{l}5^{*} 10^{9} / \text { time, } 4 \text { times/ } \\
\text { cycle, } 4 \text { cycles (IV) }\end{array}$ & DP & WHO & Unclear & After & $\mathrm{O} 1, \mathrm{O} 2$ \\
\hline $\begin{array}{l}\text { Niu, B., } \\
2014 \text { [55] }\end{array}$ & III-IV & $30 / 30$ & Unclear & $32-77$ & $\begin{array}{l}\text { DC-CIK } \\
\text { cells }\end{array}$ & $\begin{array}{l}\text { Unclear, } 3 \text { times/ } \\
\text { cycle, } 1 \text { cycle (IV) }\end{array}$ & GP & RECIST & Unclear & After & $\mathrm{O} 1, \mathrm{O} 2$ \\
\hline $\begin{array}{l}\text { Zhang, M., } \\
2014 \text { [56] }\end{array}$ & IIIa-IV & $136 / 136$ & $139 / 133$ & $18-75$ & $\begin{array}{l}\text { Ag-DC-CIK } \\
\text { cells }\end{array}$ & $\begin{array}{c}>1^{*} 10^{10} / \text { cycle, } \\
4 \text { times/cycle, } \\
1 \text { cycle }(\mathrm{IV})\end{array}$ & TP, DP & RECIST & FCM & After & $\mathrm{O} 1, \mathrm{O} 2$ \\
\hline $\begin{array}{l}\text { Cheng, C., } \\
2015 \text { [57] }\end{array}$ & Unclear & $40 / 40$ & $54 / 26$ & $30-73$ & $\begin{array}{l}\text { DC-CIK } \\
\text { cells }\end{array}$ & $\begin{array}{l}\text { Unclear, } 8 \text { times/ } \\
\text { cycle, } 3 \text { cycles (IV) }\end{array}$ & $\mathrm{TP}$ & WHO & FCM & After & $\mathrm{O} 1, \mathrm{O} 2$ \\
\hline $\begin{array}{l}\text { Li, S., } \\
2015[42]\end{array}$ & III-IV & $26 / 25$ & $25 / 26$ & $70-81$ & $\begin{array}{l}\text { DC-CIK } \\
\text { cells }\end{array}$ & $\begin{array}{l}\text { Unclear, } 2 \text { times/ } \\
\text { cycle, 2-6cycles (IV) }\end{array}$ & GP & RECIST & FCM & $1 \mathrm{w}$ & $\mathrm{O} 1, \mathrm{O} 2$ \\
\hline $\begin{array}{l}\text { Qu, Y., } \\
2015[58]\end{array}$ & IIIb-IV & $50 / 50$ & $62 / 38$ & $36-77$ & $\begin{array}{l}\text { DC-CIK } \\
\text { cells }\end{array}$ & $\begin{array}{l}4-5^{*} 10^{9} / \text { cycle, } \\
4 \text { times/cycle, } \\
6 \text { cycles (IV) }\end{array}$ & $\mathrm{TP}$ & RECIST & FCM & $1 \mathrm{w}$ & $\mathrm{O} 1, \mathrm{O} 2$ \\
\hline $\begin{array}{l}\text { Wang, Y., } \\
2015 \text { [59] }\end{array}$ & Advanced & $30 / 30$ & $35 / 25$ & $40-65$ & $\begin{array}{l}\text { DC-CIK } \\
\text { cells }\end{array}$ & $\begin{array}{l}\text { Unclear, 8-10 times/ } \\
\text { cycle, } 2 \text { cycles (IV) }\end{array}$ & NP & Unclear & Unclear & $4 \mathrm{w}$ & $\mathrm{O} 1, \mathrm{O} 2$ \\
\hline $\begin{array}{l}\text { Xu, H., } \\
2015[60]\end{array}$ & III-IV & $42 / 42$ & $56 / 28$ & $54-79$ & $\begin{array}{l}\text { DC-CIK } \\
\text { cells }\end{array}$ & $\begin{array}{c}\text { DC: }>1^{*} 10^{7} / \text { time, } 4 \\
\text { times, CIK: }>1^{*} 10^{9} / \\
\text { time, } 2 \text { times, } 2 \text { cycles }\end{array}$ & $\mathrm{TP}$ & RECIST & FCM & After & $\mathrm{O} 1, \mathrm{O} 2$ \\
\hline $\begin{array}{l}\text { Yang, L., } \\
2015 \text { [61] }\end{array}$ & IIIa-IV & $36 / 36$ & $47 / 25$ & $38-77$ & $\begin{array}{l}\text { DC-CIK } \\
\text { cells }\end{array}$ & $\begin{array}{c}>1 * 10^{10} / \text { time, } \\
4 \text { times/cycle, } \\
1 \text { cycle }(\text { IV })\end{array}$ & $\mathrm{TN}$ & RECIST & FCM & $2 w$ & $\mathrm{O} 1, \mathrm{O} 2$ \\
\hline $\begin{array}{l}\text { Zhao, H., } \\
2015[62]\end{array}$ & II-IIIb & $45 / 45$ & $66 / 24$ & $50-79$ & $\begin{array}{l}\text { DC-CIK } \\
\text { cells }\end{array}$ & $\begin{array}{l}5^{*} 10^{9} / \text { time, } 5 \text { times/ } \\
\text { cycle, } 4 \text { cycles (IV) }\end{array}$ & $\mathrm{PP}$ & No & FCM & After & $\mathrm{O} 1$ \\
\hline $\begin{array}{l}\text { Dong, Q., } \\
2016[63]\end{array}$ & III-IV & $26 / 26$ & $28 / 24$ & $52-77$ & $\begin{array}{l}\text { DC-CIK } \\
\text { cells }\end{array}$ & $\begin{array}{l}>1^{*} 10^{10} / \text { cycle, } \\
5 \text { times/cycle, } \\
4 \text { cycles (IV) }\end{array}$ & $\mathrm{PP}$ & RECIST & FCM & $1 \mathrm{w}$ & $\mathrm{O} 1, \mathrm{O} 2$ \\
\hline $\begin{array}{l}\text { Dong, Z., } \\
2016[64]\end{array}$ & Advanced & $45 / 45$ & $46 / 44$ & $43-80$ & $\begin{array}{l}\text { DC-CIK } \\
\text { cells }\end{array}$ & $\begin{array}{c}1.0^{*} 10^{9} / \text { time, } 24 \\
\text { times/cycle, } 1 \text { cycle }\end{array}$ & NP & No & Unclear & After & O1 \\
\hline $\begin{array}{l}\text { Wu, M., } \\
2016[65]\end{array}$ & IIIb-IV & $35 / 35$ & $52 / 18$ & Unclear & $\begin{array}{l}\text { DC-CIK } \\
\text { cells }\end{array}$ & $\begin{array}{c}\text { DC: } 1^{*} 10^{7} / \text { time }(\mathrm{SI}) \\
\text { CIK: } 4^{*} 10^{9} / \text { time }(\mathrm{IV}) \\
5 \text { times, } 4 \text { cycles }\end{array}$ & $\mathrm{TP}$ & WHO & FCM & $4 \mathrm{w}$ & $\mathrm{O} 1, \mathrm{O} 2$ \\
\hline
\end{tabular}


TABLE 1: Continued.

\begin{tabular}{|c|c|c|c|c|c|c|c|c|c|c|c|}
\hline \multirow{2}{*}{$\begin{array}{l}\text { First } \\
\text { author, } \\
\text { year }\end{array}$} & \multicolumn{4}{|c|}{ NSCLC } & \multicolumn{3}{|c|}{ Interventions } & \multirow[b]{2}{*}{ Criteria } & \multirow[b]{2}{*}{ Detecting } & \multirow[b]{2}{*}{ Time } & \multirow[b]{2}{*}{$\mathrm{O}$} \\
\hline & Stage & $\mathrm{E} / \mathrm{C}$ & $\mathrm{M} / \mathrm{F}$ & Years & Cells & Usage & $\mathrm{C}$ & & & & \\
\hline $\begin{array}{l}\text { Yang, J., } \\
2016[66]\end{array}$ & IIIb-IV & $60 / 60$ & $54 / 66$ & Unclear & $\begin{array}{l}\text { Ag-DC-CIK } \\
\text { cells }\end{array}$ & $\begin{array}{c}\text { Unclear, } 1 \text { time/cycle, } \\
2 \text { cycles (IV) }\end{array}$ & $\mathrm{PP}$ & RECIST & FCM & After & $\mathrm{O} 1, \mathrm{O} 2$ \\
\hline $\begin{array}{l}\text { Yang, Y., } \\
2016 \text { [67] }\end{array}$ & Advanced & $24 / 28$ & $29 / 23$ & $65-75$ & $\begin{array}{l}\text { DC-CIK } \\
\text { cells }\end{array}$ & $\begin{array}{c}>1.0^{*} 10^{9} / \text { cycle, } 6 \\
\text { times/cycle, } 1 \text { cycle }\end{array}$ & $\mathrm{TP}$ & RECIST & Unclear & After & $\mathrm{O} 1$ \\
\hline $\begin{array}{l}\text { Zhang, C., } \\
2016 \text { [68] }\end{array}$ & IIb-IIIb & $43 / 43$ & $51 / 35$ & $40-83$ & $\begin{array}{l}\text { DC-CIK } \\
\text { cells }\end{array}$ & $\begin{array}{l}5^{*} 10^{9} / \text { time, } 4 \text { times/ } \\
\text { cycle, } 2-6 \text { cycles (IV) }\end{array}$ & GP & Unclear & Unclear & After & $\mathrm{O} 1, \mathrm{O} 2$ \\
\hline $\begin{array}{l}\text { Zhang, Z., } \\
\text { 2016[69] }\end{array}$ & IIIb-IV & $60 / 60$ & $104 / 16$ & $29-82$ & $\begin{array}{l}\text { Ag-DC-CIK } \\
\text { cells }\end{array}$ & $\begin{array}{l}\text { DC: }-, 2 \text { times, CIK: } \\
>1^{*} 10^{8} / \text { time, } 3 \text { times/ } \\
\text { cycle, unclear }(\mathrm{IV})\end{array}$ & Chemo* & RECIST & FCM & After & $\mathrm{O} 1, \mathrm{O} 2$ \\
\hline $\begin{array}{l}\text { Wang, Y., } \\
2017[31]\end{array}$ & IIIa-IV & $29 / 30$ & $36 / 23$ & $35-76$ & $\begin{array}{l}\text { DC-CIK } \\
\text { cells }\end{array}$ & $\begin{array}{c}1.0^{*} 10^{9} / \text { time, } 8 \text { times/ } \\
\text { cycle, } 3 \text { cycles (IV) }\end{array}$ & $\mathrm{NP}$ & Unclear & FCM & After & $\mathrm{O} 1, \mathrm{O} 2$ \\
\hline $\begin{array}{l}\text { Zhao, H., } \\
2017[32]\end{array}$ & IIIb-IV & $30 / 30$ & $37 / 23$ & Unclear & $\begin{array}{l}\text { Ag-DC-CIK } \\
\text { cells }\end{array}$ & $\begin{array}{c}\text { DC: }-, 1 \text { time }(\mathrm{SI}) ; \\
\text { CIK: }-, 1 \text { time }(\mathrm{IV}), 2 \\
\text { cycles }\end{array}$ & GP & RECIST & FCM & After & $\mathrm{O} 1, \mathrm{O} 2$ \\
\hline $\begin{array}{l}\text { Zhou, S., } \\
2017 \text { [33] }\end{array}$ & II-IV & $43 / 43$ & $58 / 28$ & $32-70$ & $\begin{array}{l}\text { DC-CIK } \\
\text { cells }\end{array}$ & $\begin{array}{l}\text { Unclear, } 5 \text { times/ } \\
\text { cycle, } 1 \text { cycle (IV) }\end{array}$ & GP & RECIST & FCM & After & $\mathrm{O} 1, \mathrm{O} 2$ \\
\hline
\end{tabular}

Note: NSCLC: non-small-cell lung cancer; E: experimental group (DC-CIK plus chemotherapy); C: control group (chemotherapy); chemo*: chemotherapy; DP docetaxel and cisplatin; TP: paclitaxel and cisplatin; TN: paclitaxel and nedaplatin; GP: gemcitabine and cisplatin; GP*: gemcitabine and platinum; NP: vinorelbine and cisplatin; PP: pemetrexed and cisplatin; ALIMTA: pemetrexed disodium for injection; GO*: gemcitabine and oxaliplatin; EP: etoposide and cisplatin; IV: intravenous injection; SI: subcutaneous injection lymph node-rich region; WHO: World Health Organization guidelines for solid tumor responses; RECIST: response evaluation criteria in solid tumors; FCM: flow cytometry; Outcomes: O1: cellular immunity; O2: tumor responses.

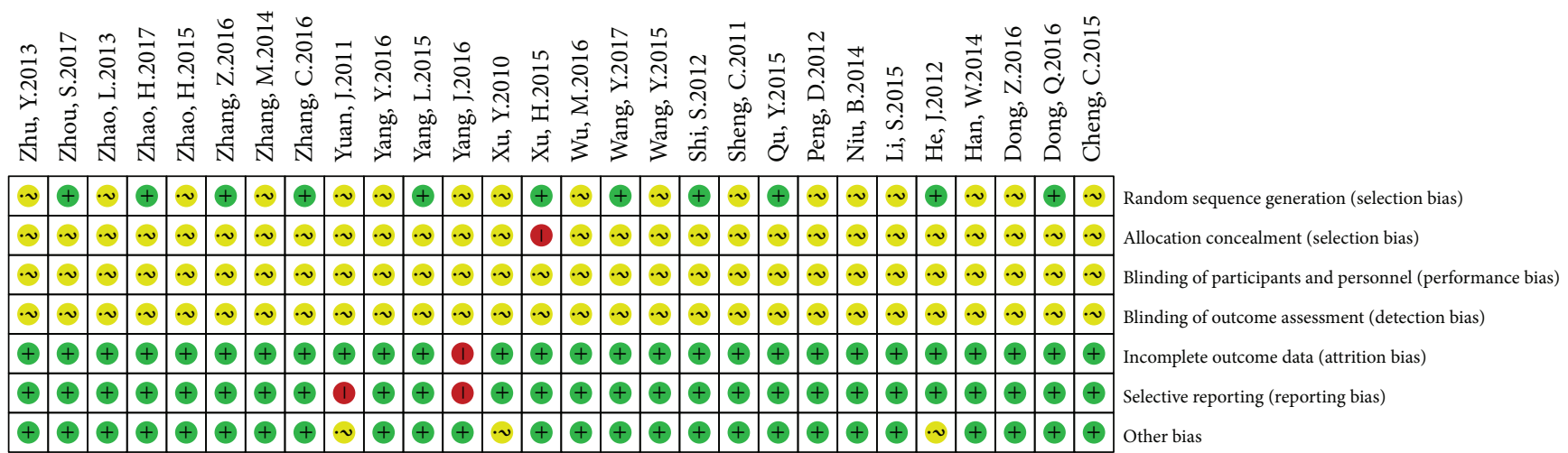

Risk of bias summary

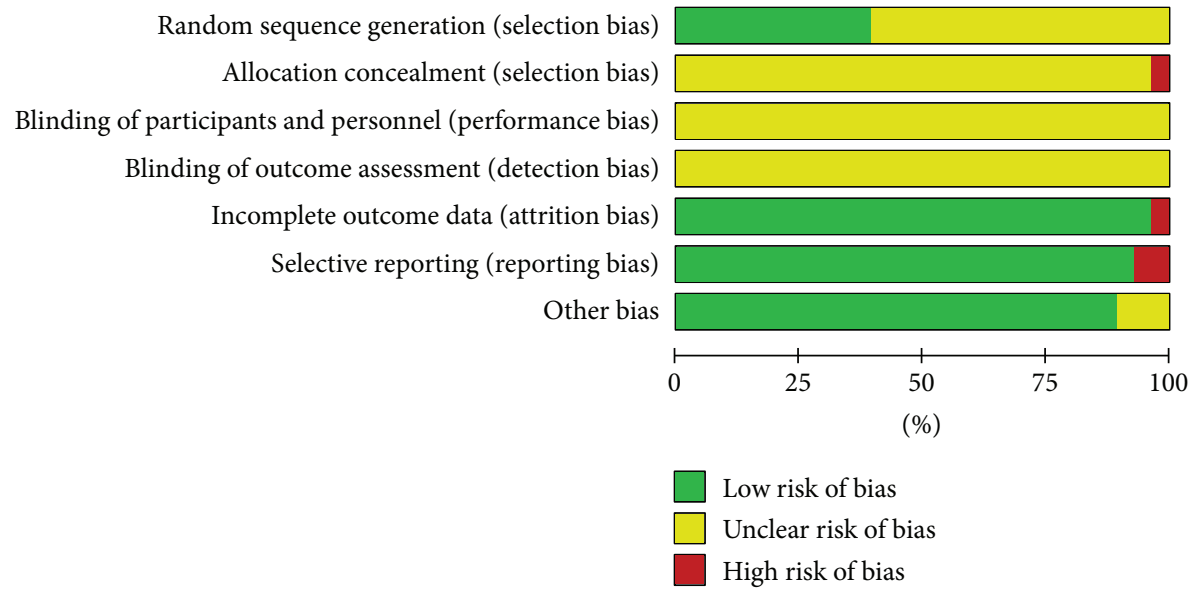

Risk of bias graph

Figure 2: Methodological bias risk of included trials. 


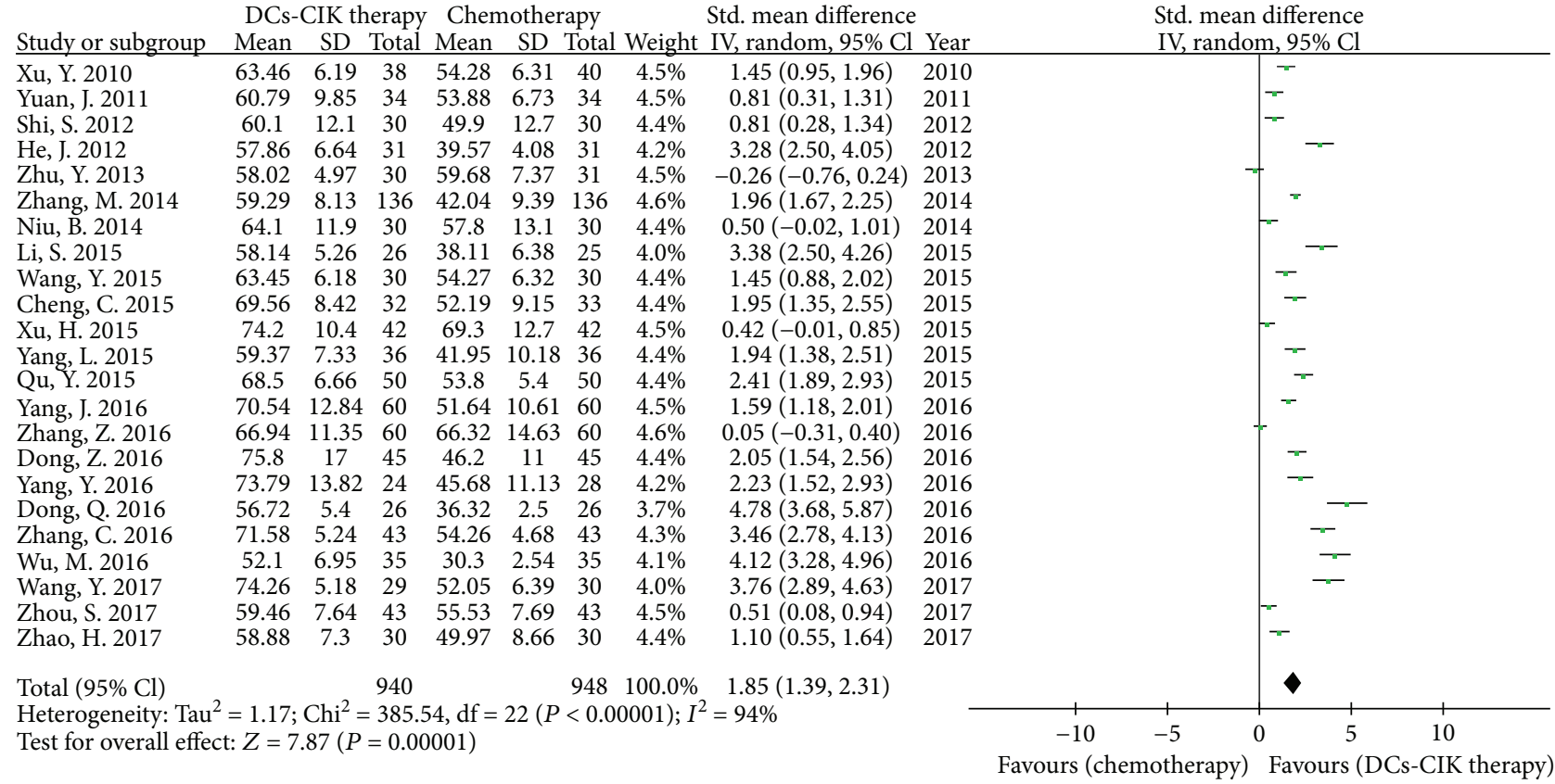

Figure 3: The analysis of $\mathrm{CD}^{+} \mathrm{T}$ cells between the two groups.

DCs-CIK therapy Chemotherapy Std. mean difference

Study or subgroup Mean SD Total Mean SD Total Weight IV, random, 95\% Cl Yea

$\begin{array}{llllllll}36.43 & 4.51 & 38 & 33.52 & 4.44 & 40 & 4.5 \% & 0.64(0.19 .1 .10)\end{array}$

$\begin{array}{llllllllll}\text { Yuan, J. 2011 } & 34.81 & 7.07 & 34 & 29.38 & 4.99 & 34 & 4.3 \% & 0.88(0.38 .1 .38) & 2011\end{array}$

Shi, S. 2012

He, J. 2012

Zhu, Y. 2013

Zhao, L. 2013

Niu, B. 2014

Zhang, M. 2014

Wang, Y. 2015

Yang, L. 2015

Ou, Y. 2015

Li, S. 2015

Xu, H. 2015

Cheng, C. 2015

Dong, Q. 2016

Yang, Y. 2016

Yang, J. 2016

Zhang, Z. 2016

Wu, M. 2016

Dong, Z. 2016

Wang, Y. 2017

Zhao, H. 2017

Zhou, S. 2017

Total $(95 \% \mathrm{Cl})$ $\begin{array}{lllllll}40.1 & 9.6 & 30 & 32.3 & 9.4 & 30 & 4.2 \%\end{array}$ $\begin{array}{lllllll}30.29 & 9.12 & 31 & 23.15 & 3.82 & 31 & 4.2 \%\end{array}$ $\begin{array}{lllllll}36.26 & 5.31 & 30 & 33.32 & 6.58 & 31 & 4.3 \%\end{array}$ $\begin{array}{lllllll}38.81 & 7.59 & 36 & 25.64 & 4.04 & 36 & 4.0 \%\end{array}$ $\begin{array}{lllllll}40.9 & 10.4 & 30 & 28.1 & 9.8 & 30 & 4.1 \%\end{array}$

$\begin{array}{lllllll}32.59 & 7.37 & 136 & 28.79 & 7.15 & 136 & 5.2 \%\end{array}$

$\begin{array}{lllllll}36.42 & 4.53 & 30 & 33.51 & 4.43 & 30 & 4.3 \%\end{array}$

$\begin{array}{lllllll}31.98 & 8.47 & 36 & 29.48 & 9.33 & 36 & 4.5 \%\end{array}$

$\begin{array}{lllllll}22.7 & 3.6 & 50 & 22.8 & 2.7 & 50 & 4.7 \%\end{array}$

$\begin{array}{lllllll}31.22 & 7.05 & 26 & 25.03 & 4.16 & 25 & 4.0 \%\end{array}$

$\begin{array}{ccccccc}32.2 & 11.5 & 42 & 24.5 & 12.4 & 42 & 4.6 \%\end{array}$

$\begin{array}{lllllll}35.78 & 3.33 & 40 & 26.18 & 4.87 & 40 & 4.1 \%\end{array}$

$\begin{array}{lllllll}36.17 & 5.59 & 26 & 30.16 & 2.84 & 26 & 3.9 \%\end{array}$

$\begin{array}{lllllll}42.05 & 8.99 & 24 & 23.76 & 11.22 & 28 & 3.8 \%\end{array}$

$\begin{array}{lllllll}39.51 & 12.82 & 60 & 32.25 & 13.46 & 60 & 4.8 \%\end{array}$

$\begin{array}{lllllll}34.86 & 9.33 & 60 & 28.8 & 11.32 & 60 & 4.8 \%\end{array}$

$\begin{array}{lllllll}20.8 & 6.82 & 35 & 16 & 3.53 & 35 & 4.4 \%\end{array}$

$\begin{array}{ccccccc}30.5 & 7 & 45 & 25.7 & 8 & 45 & 4.6 \%\end{array}$

$\begin{array}{lllllll}34.12 & 5.02 & 29 & 23.65 & 6.18 & 30 & 3.9 \%\end{array}$

$\begin{array}{lllllll}40.45 & 9.96 & 30 & 34.57 & 8.93 & 30 & 4.3 \%\end{array}$

36.129 .18

941

941

Heterogeneity: $\mathrm{Tau}^{2}=0.23$; $\mathrm{Chi}^{2}=115.80, \mathrm{~d}$
Test for overall effect: $Z=7.67(P<0.00001)$
$948 \quad 100.0 \% \quad 0.87[0.65,1.10)$

$0.81(0.28 .1 .34) \quad 2012$

$1.01(0.48 .1 .54) \quad 2012$

$0.48(-0.03 .0 .99) \quad 2013$

$2.14(1.56 .2 .73) \quad 2013$

$1.25(0.69 .1 .81) \quad 2014$

$0.52(0.28 .0 .76) \quad 2014$

$0.64(0.12,1.16) \quad 2015$

$0.28(-0.19,0.74) \quad 2015$

$0.03(-0.42,0.36) 2015$

$1.05(0.46,1.64) \quad 2015$

$0.64(0.20,1.08) \quad 2015$

$2.28(1.71,2.85) \quad 2015$

$1.34(0.73,1.94) \quad 2016$

$1.76(1.11,2.41) \quad 2016$

$0.55(0.18,0.91) \quad 2016$

$0.58(0.21,0.95) \quad 2016$

$0.87(0.38,1.37) \quad 2016$

$0.63(0.21,1.06) \quad 2016$

$1.83(1.22,2.45) \quad 2017$

$0.61(0.09,1.13)-2017$

$0.10(-0.33,0.52) \quad 2017$
$+$
Std. mean difference IV, random, $95 \% \mathrm{Cl}$

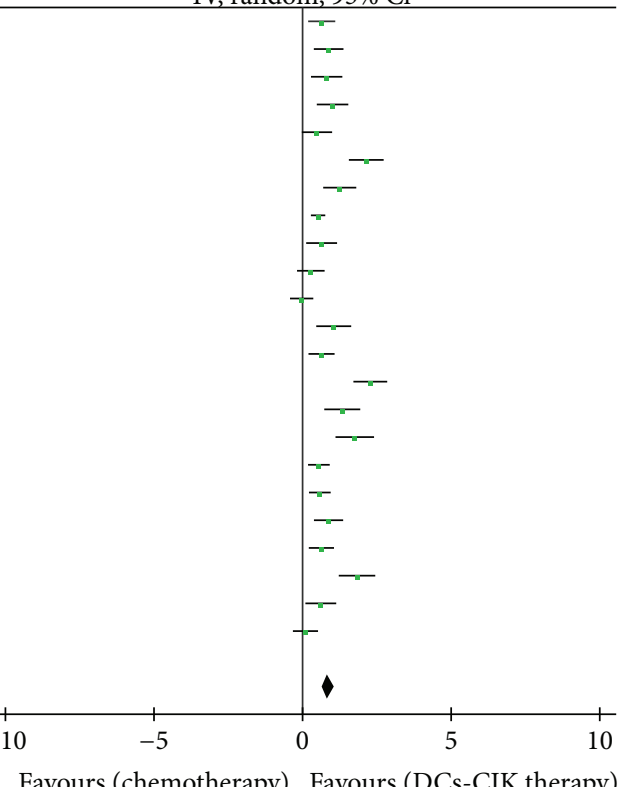

Figure 4: The analysis of $\mathrm{CD} 4^{+} \mathrm{T}$ cells between the two groups.

$\mathrm{CD}^{+} \mathrm{T}$ cells. Treatment with one cycle to four cycles could all increase the proportions of $\mathrm{CD}^{+} \mathrm{T}$ cells and $\mathrm{CD}^{+}$ $\mathrm{CD} 4^{+} \mathrm{T}$ cells. But only treatment with one cycle or two cycles could increase the ratio of $\mathrm{CD}^{+} / \mathrm{CD}^{+} \mathrm{T}$ cells (Table 2, Figure S5-8). Thirdly, combinations with taxanes, NP, GP, or pemetrexed chemotherapy, DC-CIK could increase the $\mathrm{CD}^{+} \mathrm{T}$ cells and $\mathrm{CD}^{+}{ }^{+} \mathrm{CD}^{+} \mathrm{T}$ cells. In combinations with taxanes, NP, or pemetrexed chemotherapy, DC-CIK could increase the $\mathrm{CD}^{+} \mathrm{T}$ cells. Only combinations with NP or
GP, DC-CIK could increase the ratio of $\mathrm{CD} 4^{+} / \mathrm{CD}^{+} \mathrm{T}$ cells (Table 2, Figure S9-12).

3.8. Publication Bias Analysis. The funnel plots were symmetrical in ORR (Figure 10(a)), and there was no publication bias in these trials. The funnel plots were significantly asymmetrical in $\mathrm{DCR}, \mathrm{CD}^{+} \mathrm{T}$ cells, $\mathrm{CD}^{+} \mathrm{CD}^{+} \mathrm{T}$ cells, $\mathrm{CD}^{+} \mathrm{CD}^{+}$ $\mathrm{T}$ cells, $\mathrm{CD}^{+} / \mathrm{CD}^{+} \mathrm{T}$ cell ratio, and NK cells (Figures $10(\mathrm{~b})$, $10(\mathrm{c}), 10(\mathrm{~d}), 10(\mathrm{e}), 10(\mathrm{f})$, and $10(\mathrm{~g}))$, and there was publication 


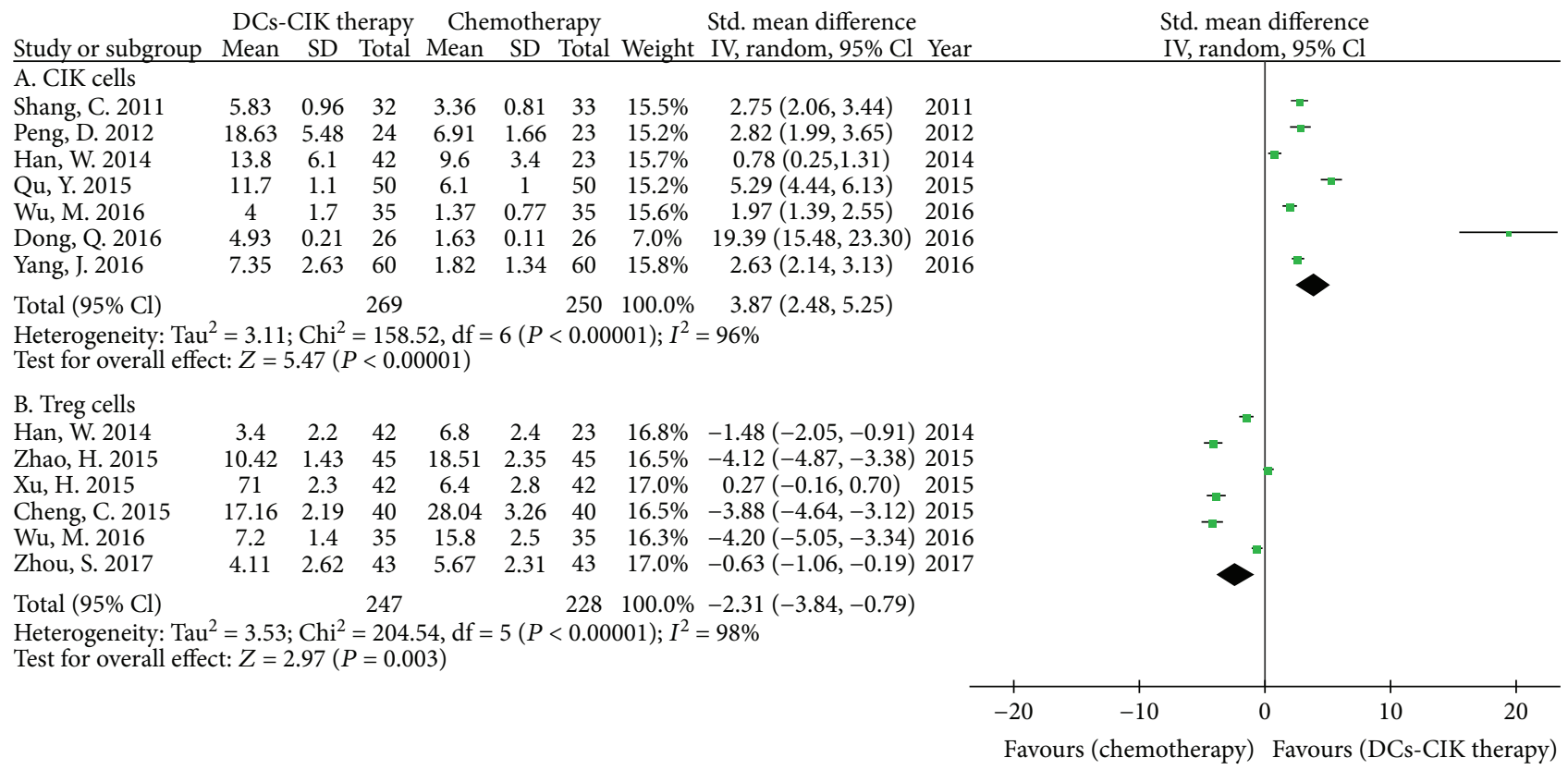

Figure 7: The analysis of CIK and Treg cells between the two groups.

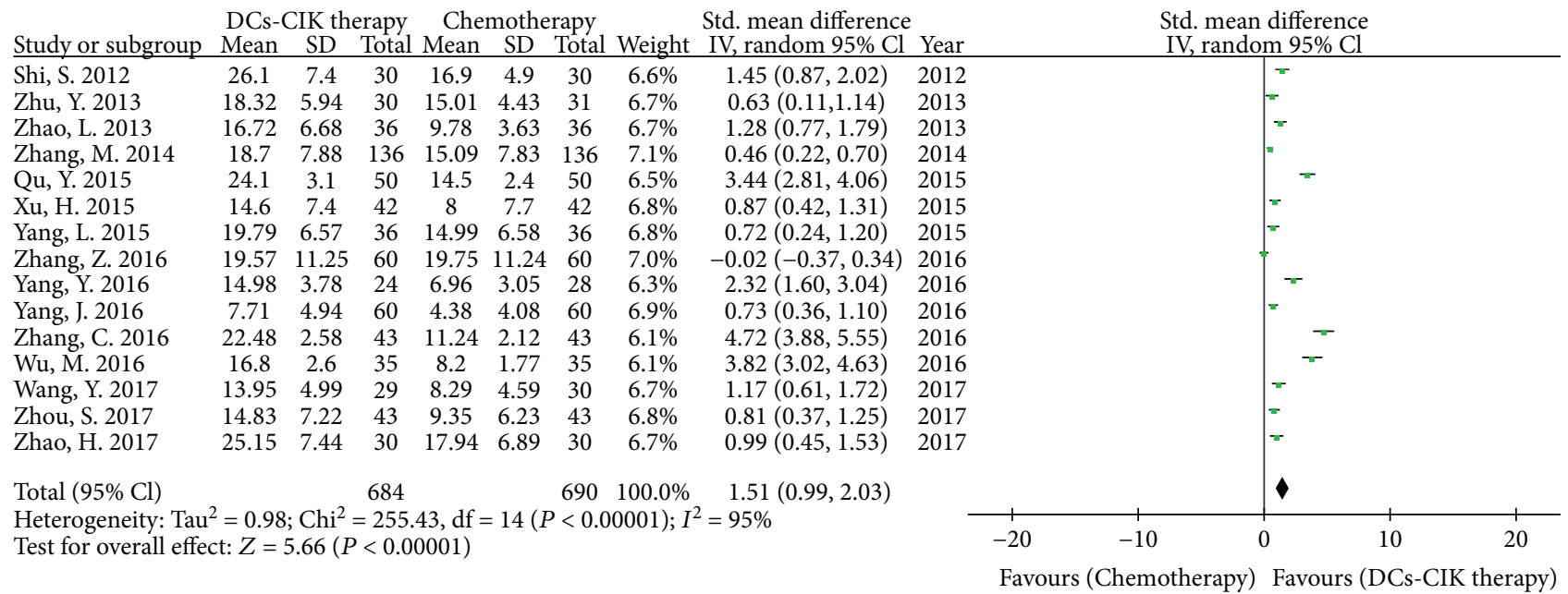

FIGURE 8: The analysis of NK cells between the two groups.

rejecting the over- or underestimated trials, all results had good consistency (Table 3(b)). In all, the meta-analysis results had good robustness.

\section{Discussion}

In this meta-analysis, we included 28 RCTs [31-33, 42, 46-69] with 2242 middle to late stage NSCLC patients without accepting surgery from China. Patients were 1311 males and 837 females between 18 and 85 years of age. DC-CIK therapy were Ag-DC-CIK cells and DC-CIK cells. The experimental groups underwent DC-CIK plus chemotherapy and the control groups underwent chemotherapy alone as DP, TP, GP, $\mathrm{NP}$, et al. The DC-CIK cells were mainly used with 1$10 \times 10^{9} /$ times, $2-6$ times/cycle, and 1-6 cycles through intravenous injection after chemotherapy. Antitumor immunity and tumor responses were, respectively, evaluated at 1-4 months after treatment.

Systematic chemotherapy significantly damage antitumor immunity, which is an important cause of poor tumor response and prognosis in patients with malignant tumors [70-72]. As an important cellular immunotherapy, the application of DC-CIK plus chemotherapy was clinically used in a wide range [20]. DC-CIK therapy were Ag-DC-CIK cells and DC-CIK cells. Previous meta-analysis [28-30] had failed to reveal whether DC-CIK cells or Ag-DC-CIK cells improve the antitumor immunity. And there was controversy whether DC-CIK therapy increase the $\mathrm{CD}^{+} \mathrm{CD}^{+} \mathrm{T}$ cells. What usage and combinations with chemotherapy could improve antitumor immunity remains unclear. In this meta-analysis, we included 28 trials with 2242 patients to evaluate the antitumor immunity. The meta-analysis results showed that 


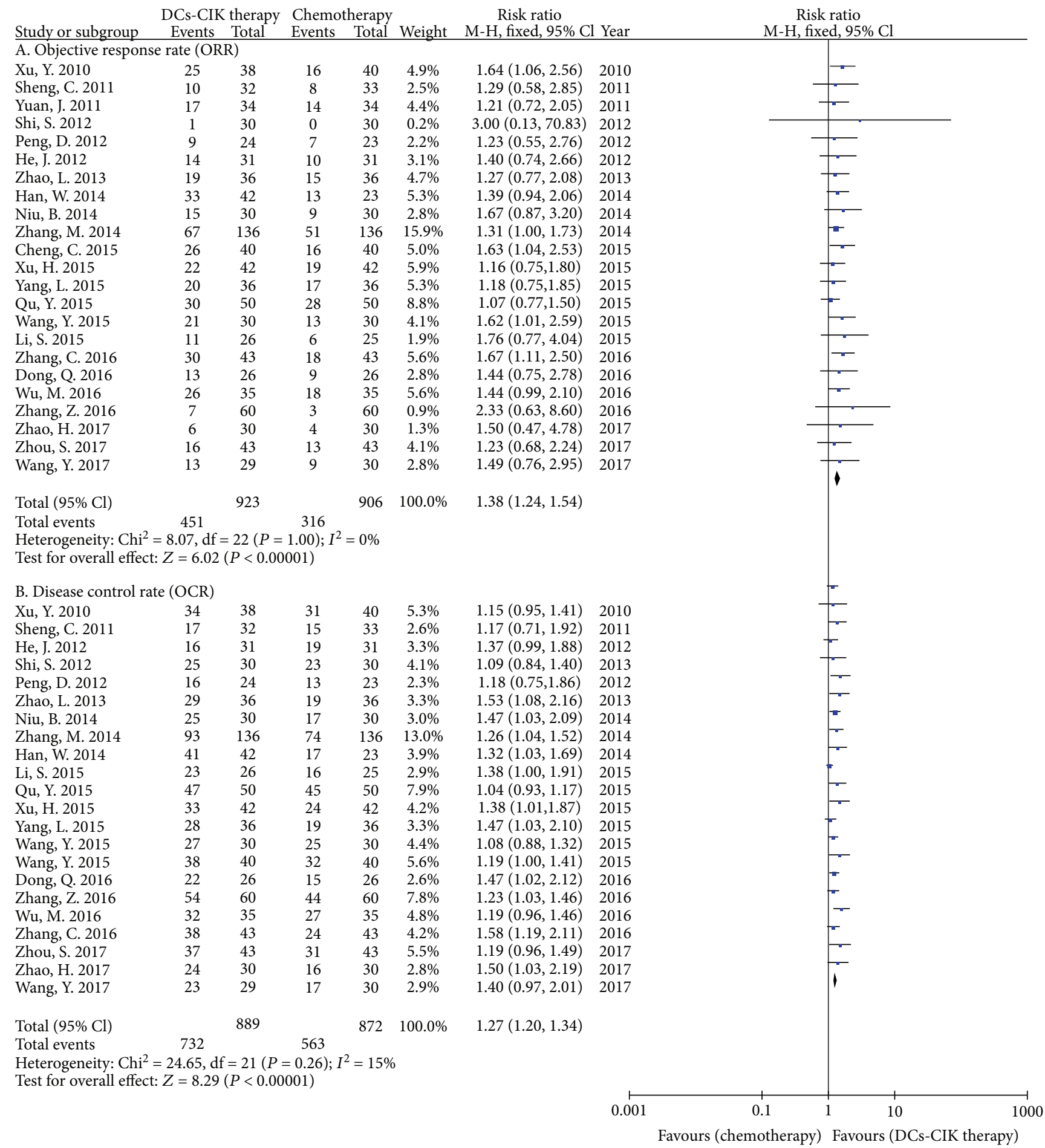

FIGURE 9: The analysis of tumor responses between the two groups.

DC-CIK therapy significantly increased the proportions of $\mathrm{CD}^{+}{ }^{+} \mathrm{T}$ cells, $\mathrm{CD}^{+}{ }^{+} \mathrm{CD} 4^{+} \mathrm{T}$ cells, $\mathrm{CD}^{+}{ }^{+} \mathrm{CD}^{+} \mathrm{T}$ cells, and the $\mathrm{CD} 4^{+} / \mathrm{CD}^{+} \mathrm{T}$ cell ratio in peripheral blood. The included trials and sample sizes were sufficient for the analysis. The sensitivity analysis showed that the results had good robustness. But most trials had unclear bias risk. To compare with previous studies [28-30], this meta-analysis further confirmed that DC-CIK therapy significantly increased the proportions of $\mathrm{T}$ lymphocyte subgroups in peripheral blood. We found that DC-CIK therapy significantly increased the $\mathrm{CD}^{+} \mathrm{CD}^{+} \mathrm{T}$ cells. Related meta-analysis [73-75] had shown that DC-CIK could increase the $\mathrm{CD}^{+}{ }^{+} \mathrm{T}$ cells, $\mathrm{CD}^{+}$ $\mathrm{CD}^{+} \mathrm{T}$ cells, and the ratio of $\mathrm{CD} 4^{+} / \mathrm{CD}^{+} \mathrm{T}$ cells in peripheral blood of patients with hepatocellular carcinoma (HCC) or gastric cancer. These studies provide indirect evidences for this meta-analysis's results. Therefore, we believed that 


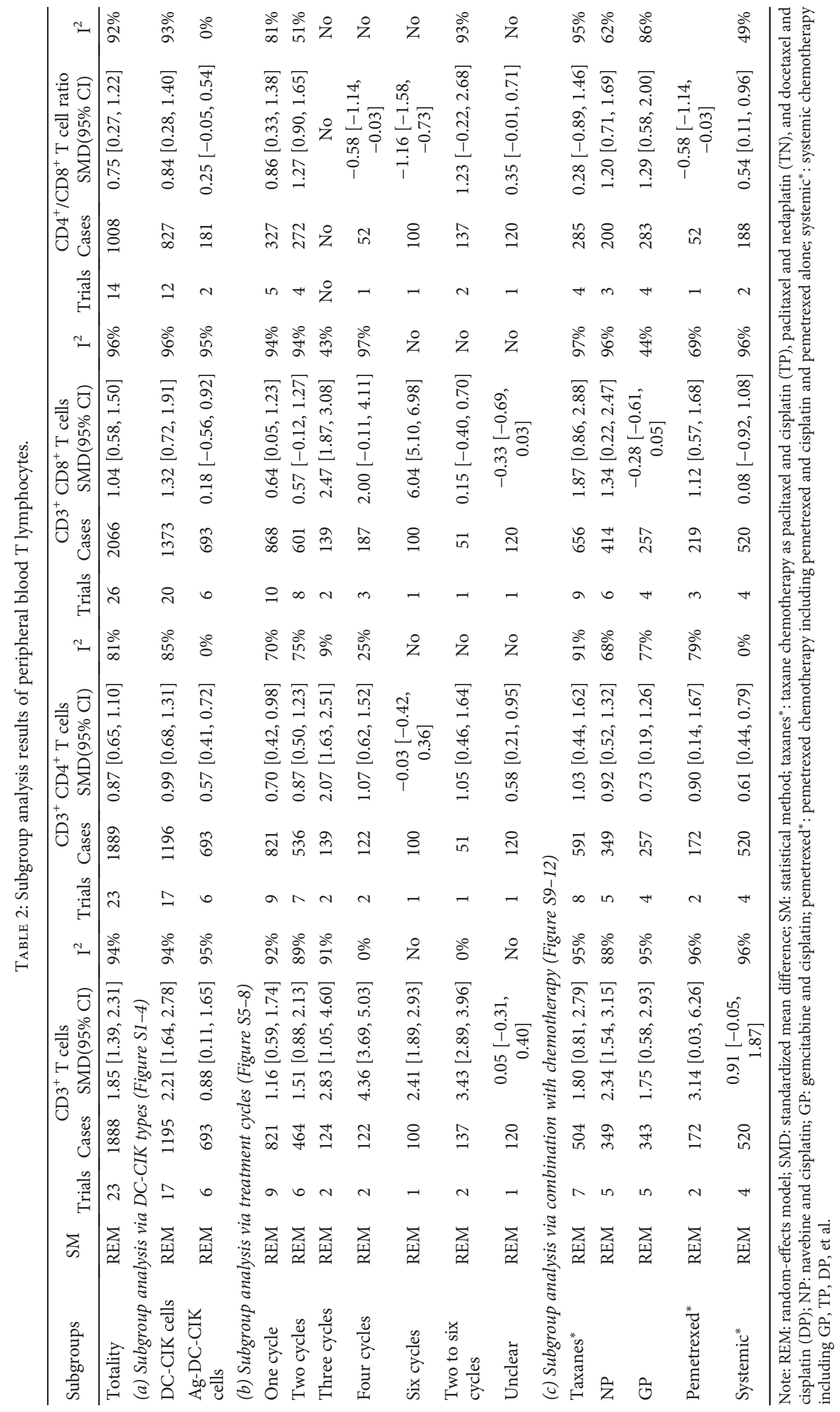




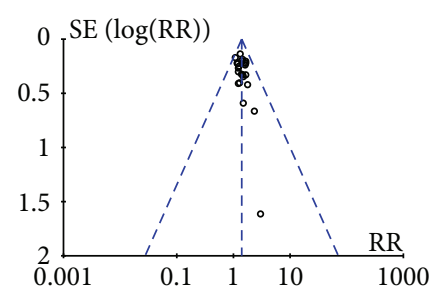

(a) ORR

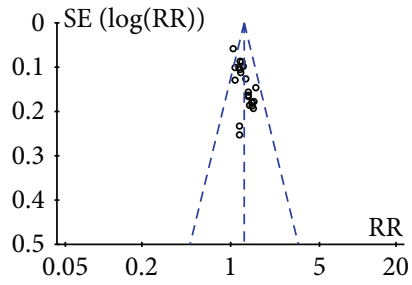

(b) DCR

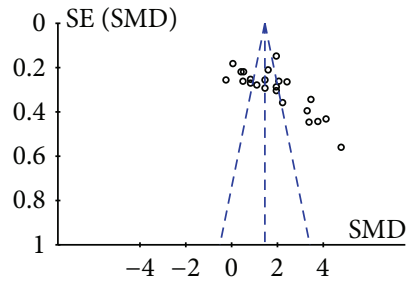

(c) $\mathrm{CD}^{+} \mathrm{T}$ cells

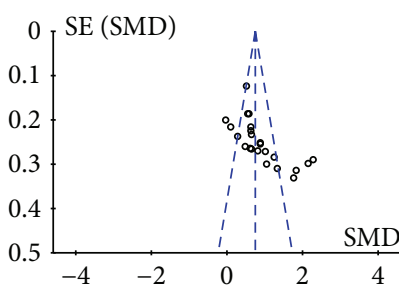

(d) $\mathrm{CD}^{+} \mathrm{CD}^{+} \mathrm{T}$ cell

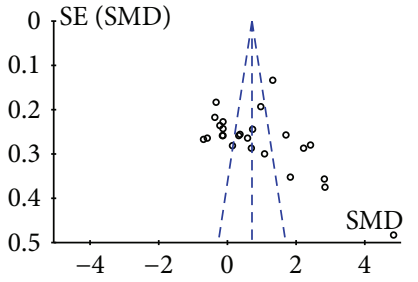

(e) $\mathrm{CD}^{+} \mathrm{CD}^{+} \mathrm{T}$ cells

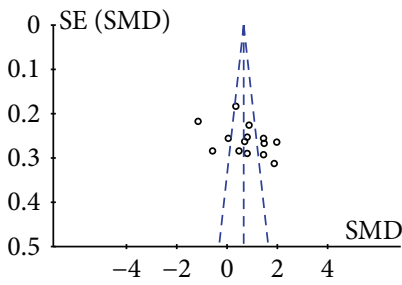

(f) $\mathrm{CD}^{+} / \mathrm{CD}^{+} \mathrm{T}$ cell ratio

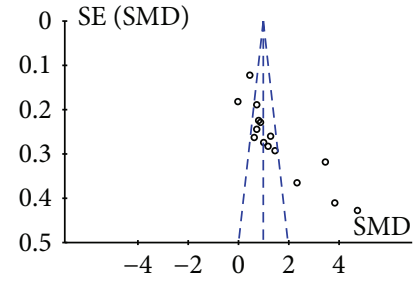

(g) NK cells

Figure 10: The analysis of publication bias.

TABLe 3: Sensitivity analysis.

(a) Sensitivity analysis through rejecting the poor trials.

\begin{tabular}{|c|c|c|c|c|c|c|c|c|c|}
\hline Indicators & Trials & SM & Effect estimate SMD (95\% CI) & $I^{2}$ & Rejected trials* & Trials & SM & Effect estimate SMD (95\% CI) & $I^{2}$ \\
\hline ORR & 23 & FEM & $1.38[1.24,1.54]$ & $0 \%$ & Poor* $[48,60]$ & 21 & FEM & $1.41[1.26,1.57]$ & $0 \%$ \\
\hline DCR & 22 & FEM & $1.27[1.20,1.34]$ & $15 \%$ & Poor* $[60]$ & 21 & FEM & $1.27[1.20,1.34]$ & $16 \%$ \\
\hline $\mathrm{CD}^{+}{ }^{+} \mathrm{T}$ cells & 23 & REM & $1.85[1.39,2.31]$ & $94 \%$ & Poor* $[60,66]$ & 21 & REM & $1.93[1.43,2.44]$ & $94 \%$ \\
\hline $\mathrm{CD}^{+}{ }^{+} \mathrm{T}$ cells & 23 & REM & $0.87[0.65,1.10]$ & $81 \%$ & Poor* $[60,66]$ & 21 & REM & $0.91[0.66,1.15]$ & $83 \%$ \\
\hline $\mathrm{CD}^{+} \mathrm{T}$ cells & 26 & REM & $1.04[0.58,1.50]$ & $96 \%$ & Poor* $[60,66]$ & 24 & REM & $1.02[0.52,1.51]$ & $96 \%$ \\
\hline NK cells & 15 & REM & $1.51[0.99,2.03]$ & $95 \%$ & Poor* $[60,66]$ & 13 & REM & $1.63[1.01,2.25]$ & $95 \%$ \\
\hline CIK cells & 7 & REM & $3.87[2.48,5.25]$ & $96 \%$ & Poor* [66] & 6 & REM & $4.33[2.56,6.11]$ & $97 \%$ \\
\hline
\end{tabular}

(b) Sensitivity analysis through rejecting the over- or underestimated trials.

\begin{tabular}{|c|c|c|c|c|c|c|c|c|c|}
\hline Indicators & Trials & SM & $\begin{array}{l}\text { Effect estimate } \\
\text { SMD }(95 \% \mathrm{CI})\end{array}$ & $\mathrm{I}^{2}$ & Rejected trials* & Trials & SM & $\begin{array}{l}\text { Effect estimate SMD } \\
(95 \% \mathrm{CI})\end{array}$ & $\mathrm{I}^{2}$ \\
\hline DCR & & FEM & $1.27[1.20,1.34]$ & $15 \%$ & Over* $[52,68]$ & 20 & FEM & $1.25[1.18,1.32]$ & $0 \%$ \\
\hline $\mathrm{CD}^{+} \mathrm{T}$ cells & 23 & REM & $1.85[1.39,2.31]$ & $94 \%$ & $\begin{array}{c}\text { Over* }^{*} \\
{[31,32,42,46,49,56-59,61,63-68]} \\
\text { under* }[53]\end{array}$ & 6 & FEM & $0.45[0.27,0.63]$ & $43 \%$ \\
\hline $\mathrm{CD} 4^{+} \mathrm{T}$ cells & 23 & REM & $0.87[0.65,1.10]$ & $81 \%$ & Over* $[31,52,57,67]$ & 12 & FEM & $0.47[0.35,0.58]$ & $16 \%$ \\
\hline $\mathrm{CD}^{+} \mathrm{T}$ cells & 26 & REM & $1.04[0.58,1.50]$ & $96 \%$ & $\begin{array}{c}\text { Over* }[31,47,50,56-58,60,64-67] \\
\text { under* }[32,33,51,52,69]\end{array}$ & 10 & FEM & $0.22[0.06,0.38]$ & $50 \%$ \\
\hline $\begin{array}{l}\mathrm{CD} 4^{+} / \mathrm{CD} 8^{+} \mathrm{T} \\
\text { cell ratio }\end{array}$ & 15 & REM & $0.74[0.30,1.19]$ & $92 \%$ & $\begin{array}{c}\text { Over* }[46,52,55,59,68] \\
\text { under* }[58,63]\end{array}$ & 8 & FEM & $0.56[0.38,0.74]$ & $34 \%$ \\
\hline NK cells & 15 & REM & $1.51[0.99,2.03]$ & $95 \%$ & Over* $[51,58,65,67,68] ;$ under* $[69]$ & 9 & FEM & $0.74[0.60,0.87]$ & $39 \%$ \\
\hline CIK cells & 7 & REM & $3.87[2.48,5.25]$ & $96 \%$ & Over* $[58,63] ;$ under* $[54]$ & 4 & FEM & $2.50[2.19,2.80]$ & $35 \%$ \\
\hline Treg cells & 6 & REM & $-2.31[-3.84,-0.79]$ & $98 \%$ & Over* $[57,62,65]$; under* $[60]$ & 2 & REM & $-1.03[-1.87,-0.20]$ & $82 \%$ \\
\hline
\end{tabular}

Note: RR: risk ratios; SMD: standardized mean difference; FEM: fixed-effects model; REM: random-effects model; CI: confidence interval; NK cells: natural killer cells; CIK cells: cytokine-induced killer cells; Treg cells: regulatory T cells; poor*: poor trials that had at least one domain considered as high risk of bias; over* or under*: over- or underestimated trials when the results had statistical difference and positive effects on publication bias or heterogeneity.

DC-CIK therapy could significantly improve the antitumor immunity through upregulating the T lymphocytes. To show the clinical heterogeneity and its influence on T lymphocyte subsets and reveal the optimal usages and combination with chemotherapy of DC-CIK, subgroup analyses were performed according to the DC-CIK types, treatment cycles, and different chemotherapy. Subgroup analyses showed that DC-CIK cells significantly increase the T lymphocyte subsets. 
Ag-DC-CIK cells only increase the $\mathrm{CD}^{+}{ }^{+} \mathrm{T}$ cells and $\mathrm{CD}^{+}$ $\mathrm{CD}^{+} \mathrm{T}$ cells. Therefore, whether Ag-DC-CIK cells improve the increase the $\mathrm{T}$ lymphocyte subsets still remains unclear. DC-CIK therapy was used with one cycle to six cycles. What was the optimal treatment cycle? The subgroup analysis showed that treatment with one cycle or two cycles, DCCIK therapy could increase the $\mathrm{CD} 4^{+} / \mathrm{CD}^{+} \mathrm{T}$ cell ratio. In addition, combinations with chemotherapies had complex and diverse characteristics. What was the optimal combinations? Further analysis revealed that only combinations with NP or GP, DC-CIK therapy could increase the $\mathrm{CD} 4^{+} / \mathrm{CD} 8^{+} \mathrm{T}$ cell ratio. The results revealed that the DC-CIK types, treatment cycles, and combinations with chemotherapy were all important factors of clinical heterogeneity. To compare with previous studies [28-30], we further found that only DC-CIK cells could improve antitumor immunity through upregulating the T lymphocyte subsets in peripheral blood. Furthermore, only treatment with one cycle or two cycles, and combinations with NP or GP, DC-CIK therapy could improve the antitumor immunity through upregulating the $\mathrm{CD}^{+} / \mathrm{CD}^{+} \mathrm{T}$ cell ratio.

CIK cells and NK cells are important effector cells in antitumor immunity. Can DC-CIK therapy increase the effector cells as CIK cells and NK cells? The meta-analysis results showed that DC-CIK therapy significantly increased the NK cells and CIK cells. Sensitivity analysis revealed that the results had good consistency. To compare with previous studies [28-30], this meta-analysis further revealed that DC-CIK could improve antitumor immunity though upregulating the CIK cells and NK cells. In addition, the regulatory $\mathrm{T}$ cells play an important role in immune tolerance and are important factors for downregulating the antitumor immunity. Therefore, how to break immune tolerance and downregulate the Treg cells also is an important way for antitumor immunotherapy. Six trials with 475 cases were included to reveal whether DC-CIK downregulate the Treg cells. The meta-analysis showed that DC-CIK therapy significantly decreased the proportions of Treg cells. But the included trials and sample sizes were insufficient for the analysis. Therefore, we believed that DC-CIK therapy might break immune tolerance through downregulating the Treg cells. In summary, DC-CIK therapy, especially DC-CIK cells, significantly improves antitumor immunity though upregulating the T lymphocyte subsets, NK cells, and CIK cells in peripheral blood. It also may improve antitumor immunity through downregulating the Treg cells and breaking the immune tolerance. Furthermore, only treatment with one cycle or two cycles, and combinations with NP or GP, DC-CIK therapy significantly improve the antitumor immunity. Therefore, we speculate that the one cycle to two cycles may be optimal cycle and the NP or GP might be optimal combinations. But whether Ag-DC-CIK cells improve the $\mathrm{T}$ lymphocytes still remains unclear. All these need to be revealed by new research.

Antitumor immunity only is secondary and short-term indicators for clinical efficacy. However, can DC-CIK therapy improve the tumor responses? In 28 trials, only 24 trials [31-33, 42, 46-52, 54-61, 63, 65, 66, 68, 69] with 1949 cases reported the tumor responses. The meta-analysis results revealed that DC-CIK plus chemotherapy increased the ORR and DCR. Sensitivity analysis showed that the results had good robustness. But, most trials had unclear bias risk. To compare with previous studies [28-30], this metaanalysis further confirmed that DC-CIK therapy improved the tumor responses. In vitro and vivo studies [16, 76, 77] had shown that CIK cells had highly efficient killing activity against a wide range of tumor cells. Other studies [19, 78, 79] also had confirmed that CIK cells co-cultured with dendritic cells could significantly enhance the antitumor activity. These studies provide basic evidences for this conclusion. We further confirmed that DC-CIK therapy could simultaneously improve the antitumor immunity and tumor responses. The results revealed that there was a correlation between antitumor immunity and tumor responses. We speculate that the antitumor immunity might play an important role in enhancing tumor responses. Therefore, detection of antitumor immunity after treatment might be of great value in predicting the tumor responses and prognosis. However, its potential laws still need to be revealed in further study.

There were some limitations in this study. Firstly, all the trials were published in China. Secondly, only 11 trials reported the random allocation method. All the trials did not provide the detailed information about the blindings. Thirdly, there were limited trials and sample sizes in Treg cells. Fourthly, cell number also had clinical heterogeneity. We did not perform subgroup analysis to reveal the influence of cell number on the $\mathrm{T}$ lymphocyte subsets, because most studies did not report it. Fifthly, in this meta-analysis, only 24 trials [31-33, 42, 46-52, 54-61, 63, 65, 66, 68, 69] with 1949 cases reported the tumor responses. All of these limitations might lead to an insufficient assessment for the antitumor immunity and tumor responses.

The available evidences indicate that DC-CIK therapy can simultaneously improve the antitumor immunity and tumor responses. DC-CIK therapy, especially DC-CIK cells can significantly improve antitumor immunity though upregulating the T lymphocyte subsets, NK cells and CIK cells in peripheral blood. It also may improve antitumor immunity through down-regulating the Treg cells and breaking the immune tolerance. Therefore, we speculate that the one to two cycles may be optimal cycle and the NP or GP may be optimal combinations. Antitumor immunity might play an important role in enhancing the tumor responses. But whether Ag-DC-CIK cells improve the $\mathrm{T}$ lymphocytes remains unclear. But all these need to be further revealed by further larger scale clinical RCT or realworld studies. In this meta-analysis, we only reported the antitumor immunity and tumor responses. And we will further report the tumor responses, long-term survival, and safety in a new study. Finally, we hope that our results will provide valuable evidence for DC-CIK therapy, especially individualized immunotherapy.

\section{Data Availability}

Readers can access the data supporting the conclusions of the study from Figures 1-10 and Tables 1-3. And other data can 
be accessed in the Optional Supplementary Materials including checklist and Appendix 2 (Figure S1-12. Subgroup analysis). In addition, if there is any need, please email us directly (zy426f@163.com).

\section{Conflicts of Interest}

All authors declare that they have no conflicts of interest.

\section{Authors' Contributions}

Zheng Xiao, Ji-hong Feng, Ling Chen, and Xingsheng Yao are responsible for the conception and design. Zheng Xiao, Cheng-qiong Wang, and Xian-tao Zeng are responsible for the development of methodology. Ming-hua Zhou and Cheng-qiong Wang are responsible for the literature search. Shi-yu Liu and Na-na Li are responsible for the selection of Articles. Yu-zhi Wang and Yong-ping Sun are responsible for the bias risk assessment. Yu-zhi Wang and Hong-song $\mathrm{Yu}$ are responsible for the data extraction. Cheng-qiong Wang and Ming-hua Zhou are responsible for the statistical analysis. All authors are responsible for writing, review, and/or revision of the manuscript. Zheng Xiao and Jihong Feng are responsible for the study supervision. All authors reviewed the PRISMA guidelines for authorship and agreed with manuscript results and conclusions. Zheng Xiao and Ji-hong Feng contributed equally to this work.

\section{Acknowledgments}

This work was funded by the Joint Fund for Science and Technology of Guizhou Province Science and Technology Hall, Science and Technology Bureau and Affiliated Hospital of Zunyi Medical College (no. (2016)7485), High Level Innovative Talent Program in Guizhou (No.fzc 120171001), Special Funds for Academic Seedlings Training and Innovation at Zunyi Medical College (Qian Kehe Pingtai Rencai no. (2017) 5733-034), Special Funds for Science and Technology Research of Traditional Chinese and National Medicine in Guizhou (no. QZYY 2017-084), Doctoral Fund of Zunyi Medical College (no. F-617), and Planning Fund of Philosophy and Social Science in Guizhou (no. 14GZYB58).

\section{Supplementary Materials}

Appendix 1: PRISMA checklist. Appendix 2: subgroup analysis (Figure S1-12). Figure S1: subgroup analysis of $\mathrm{CD}^{+} \mathrm{T}$ cell via different DC-CIK cells. Figure S2: subgroup analysis of $\mathrm{CD} 4^{+} \mathrm{T}$ cell via different DC-CIK cells. Figure S3: subgroup analysis of $\mathrm{CD}^{+} \mathrm{T}$ cell via different DC-CIK cells. Figure S4: subgroup analysis of $\mathrm{CD} 4^{+} / \mathrm{CD}^{+} \mathrm{T}$ cell via different DC-CIK cells. Figure S5: subgroup analysis of $\mathrm{CD}^{+} \mathrm{T}$ cell via different cycles. Figure S6: subgroup analysis of $\mathrm{CD}^{+} \mathrm{T}$ cell via different cycles. Figure S7: subgroup analysis of $\mathrm{CD} 8^{+} \mathrm{T}$ cell via different cycles. Figure S8: subgroup analysis of $\mathrm{CD} 4^{+} / \mathrm{CD} 8^{+}$ $\mathrm{T}$ cell via different cycles. Figure S9: subgroup analysis of $\mathrm{CD}^{+} \mathrm{T}$ cell via different chemotherapy. Figure S10: subgroup analysis of $\mathrm{CD} 4^{+} \mathrm{T}$ cell via different chemotherapy.
Figure S11: subgroup analysis of $\mathrm{CD}^{+} \mathrm{T}$ cell via different chemotherapy. Figure S12: subgroup analysis of $\mathrm{CD}^{+} /$ $\mathrm{CD}^{+} \mathrm{T}$ cell via different chemotherapy. (Supplementary Materials)

\section{References}

[1] W. Chen, R. Zheng, P. D. Baade et al., "Cancer statistics in China, 2015," CA: a Cancer Journal for Clinicians, vol. 66, no. 2, pp. 115-132, 2016.

[2] R. L. Siegel, K. D. Miller, and A. Jemal, "Cancer statistics, 2017," CA: a Cancer Journal for Clinicians, vol. 67, no. 1, pp. 7-30, 2017.

[3] L. A. Torre, R. L. Siegel, and A. Jemal, "Lung cancer statistics," Advances in Experimental Medicine and Biology, vol. 893, pp. 1-19, 2016.

[4] D. Mathios, J. E. Kim, A. Mangraviti et al., "Anti-PD-1 antitumor immunity is enhanced by local and abrogated by systemic chemotherapy in GBM," Science Translational Medicine, vol. 8, no. 370, p. 370ra180, 2016.

[5] S. Gebremeskel and B. Johnston, "Concepts and mechanisms underlying chemotherapy induced immunogenic cell death: impact on clinical studies and considerations for combined therapies," Oncotarget, vol. 6, no. 39, pp. 41600-41619, 2015.

[6] C. Rebe and F. Ghiringhelli, "Cytotoxic effects of chemotherapy on cancer and immune cells: how can it be modulated to generate novel therapeutic strategies?," Future Oncology, vol. 11, no. 19, pp. 2645-2654, 2015.

[7] K. W. Kim, S. H. Kim, J. H. Jang et al., "Dendritic cells loaded with exogenous antigen by electroporation can enhance MHC class I-mediated antitumor immunity," Cancer Immunology, Immunotherapy, vol. 53, no. 4, pp. 315-322, 2004.

[8] R. C. Fields, K. Shimizu, and J. J. Mule, "Murine dendritic cells pulsed with whole tumor lysates mediate potent antitumor immune responses in vitro and in vivo," Proceedings of the National Academy of Sciences of the United States of America, vol. 95, no. 16, pp. 9482-9487, 1998.

[9] J. Li, L. M. Holmes, K. J. Franek, K. E. Burgin, T. E. Wagner, and Y. Wei, "Purified hybrid cells from dendritic cell and tumor cell fusions are superior activators of antitumor immunity," Cancer Immunology, Immunotherapy, vol. 50, no. 9, pp. 456-462, 2001

[10] I. G. Schmidt-Wolf, R. S. Negrin, H. P. Kiem, K. G. Blume, and I. L. Weissman, "Use of a SCID mouse/human lymphoma model to evaluate cytokine-induced killer cells with potent antitumor cell activity," The Journal of Experimental Medicine, vol. 174, no. 1, pp. 139-149, 1991.

[11] I. G. H. Schmidt-Wolf, S. Finke, B. Trojaneck et al., "Phase I clinical study applying autologous immunological effector cells transfected with the interleukin-2 gene in patients with metastatic renal cancer, colorectal cancer and lymphoma," British Journal of Cancer, vol. 81, no. 6, pp. 1009-1016, 1999.

[12] Y. C. Linn, L. C. Lau, and K. M. Hui, "Generation of cytokineinduced killer cells from leukaemic samples with in vitro cytotoxicity against autologous and allogeneic leukaemic blasts," British Journal of Haematology, vol. 116, no. 1, pp. 78-86, 2002.

[13] D. P. Li, W. Li, J. Feng, K. Chen, and M. Tao, “Adjuvant chemotherapy with sequential cytokine-induced killer (CIK) cells in stage IB non-small cell lung cancer," Oncology Research, vol. 22, no. 2, pp. 67-74, 2015. 
[14] S. Qu, Z. Liu, Z. Zheng et al., "The influence of autologous cytokine-induced killer cell treatment on the objective efficacy and safety of gefitinib in advanced non-small cell lung cancer," Oncology and Translational Medicine, vol. 1, no. 2, pp. 69-72, 2015.

[15] J. Zhang, L. Zhu, H. du et al., "Autologous cytokine-induced killer cell therapy in lung cancer patients: a retrospective study," Biomedicine \& Pharmacotherapy, vol. 70, pp. 248252, 2015.

[16] L. Pengying, C. Longbang, and H. Xiang, "The antitumor effects of CIK cells combined with docetaxel against drugresistant lung adenocarcinoma cell line SPC-A1/DTX in vitro and in vivo," Journal of Clinical Oncology, vol. 27, p. 3039, 2009.

[17] S. Zhang, S. J. Jiang, C. Q. Zhang, H. M. Wang, and C. X. Bai, "Antitumour activities of cytokine-induced killer cells and dendritic cells in vitro and in vivo," Chinese Medical Journal, vol. 118, no. 15, pp. 1308-1312, 2005.

[18] S. Zhang, E. Wang, C. Bai, and Y. Xu, “The experimental study of co-cultured dendritic cells and CIK cells for treating lung hematogenous metastasis of colon cancer," Tumor, vol. 23, pp. 448-451, 2003.

[19] Y.-F. Wang, P. E. Kunda, J. W. Lin et al., "Cytokine-induced killer cells co-cultured with complete tumor antigen-loaded dendritic cells, have enhanced selective cytotoxicity on carboplatin-resistant retinoblastoma cells," Oncology Reports, vol. 29, no. 5, pp. 1841-1850, 2013.

[20] L. C. Schmeel, F. C. Schmeel, C. Coch, and I. G. H. SchmidtWolf, "Cytokine-induced killer (CIK) cells in cancer immunotherapy: report of the international registry on CIK cells (IRCC)," Journal of Cancer Research and Clinical Oncology, vol. 141, no. 5, pp. 839-849, 2015.

[21] M. Mayor, N. Yang, D. Sterman, D. R. Jones, and P. S. Adusumilli, "Immunotherapy for non-small cell lung cancer: current concepts and clinical trials," European Journal of Cardio-Thoracic Surgery, vol. 49, no. 5, pp. 1324-1333, 2016.

[22] Z. X. Wang, J. X. Cao, M. Wang et al., “Adoptive cellular immunotherapy for the treatment of patients with breast cancer: a meta-analysis," Cytotherapy, vol. 16, no. 7, pp. 934-945, 2014.

[23] S. Valpione and L. G. Campana, "Immunotherapy for advanced melanoma: future directions," Immunotherapy, vol. 8, no. 2, pp. 199-209, 2016.

[24] H. Qian, H. Wang, X. Guan, Z. Yi, and F. Ma, “Adoptive immunotherapy combined chemoradiotherapy for non-smallcell lung cancer: a meta-analysis," Anti-Cancer Drugs, vol. 27, no. 5, pp. 433-438, 2016.

[25] R. X. Han, X. Liu, P. Pan, Y. J. Jia, and J. C. Yu, "Effectiveness and safety of chemotherapy combined with dendritic cells cocultured with cytokine-induced killer cells in the treatment of advanced non-small-cell lung cancer: a systematic review and meta-analysis," PLoS One, vol. 9, no. 9, article e108958, 2014.

[26] L. Xu, M. Zha, and X. Wu, "Meta-analysis of DC-CIK or CIK combined with chemotherapy in the treatment of advanced non-small cell lung cancer," Journal of Bengbu Medical College, vol. 39, pp. 1508-1511, 2014.

[27] X. P. Lan, Y. G. Chen, Z. Wang et al., "Immunotherapy of DCCIK cells enhances the efficacy of chemotherapy for solid cancer: a meta-analysis of randomized controlled trials in Chinese patients," Journal of Zhejiang University-Science B, vol. 16, no. 9, pp. 743-756, 2015.
[28] S. Hu, S. Zhang, and T. Cai, "Immunochemotherapy for advanced non-small cell lung cancer: a meta-analysis," Clinical Focus, vol. 30, pp. 283-289, 2015.

[29] Q. Sun, W. Ge, and Q. Song, "Clinical efficacy and safety evaluation of DC-CIK treatment combined with platinum-based chemotherapy for advanced non-small cell lung cancer," China Medical Herald, vol. 13, pp. 93-99, 2016.

[30] C. Zhou, D. Liu, J. Li et al., "Chemotherapy plus dendritic cells co-cultured with cytokine-induced killer cells versus chemotherapy alone to treat advanced non-small-cell lung cancer: a meta-analysis," Oncotarget, vol. 7, no. 52, pp. 86500-86510, 2016.

[31] Y. Wang, L. Lu, P. Liu, Y. Liu, and Y. Zhang, "Clinical effect of dendritic cells and cytokine-induced killer cells combined with chemotherapy on advanced non-small cell lung cancer," Practical Journal of Cardiac Cerebral Pneumal and Vascular Disease, vol. 25, pp. 140-142, 2017.

[32] H. Zhao, W. Su, Q. Hu et al., "Effect of DC-CIK combined with chemotherapy on advanced non-small cell lung cancer and its influence on immune function," Progress in Modern Biomedicine, vol. 17, pp. 2560-2564, 2017.

[33] S. Zhou, "Effect of DC-CIK in combined with chemotherapy on the immunological function in patients with advanced non-small cell lung cancer," Journal of Hainan Medical University, vol. 23, pp. 510-513, 2017.

[34] C. F. Mountain, "Value of the new TNM staging system for lung cancer," Chest, vol. 96, 1 Suppl, pp. 47S-49S, 1989.

[35] J. P. T. Higgins and S. Green, "Cochrane handbook for systematic reviews of interventions version 5.1.0," 2011, https://training.cochrane.org/handbook.

[36] A. B. Miller, B. Hoogstraten, M. Staquet, and A. Winkler, "Reporting results of cancer treatment," Cancer, vol. 47, no. 1, pp. 207-214, 1981.

[37] H. Watanabe, S. Yamamoto, H. Kunitoh et al., "Tumor response to chemotherapy: the validity and reproducibility of RECIST guidelines in NSCLC patients," Cancer Science, vol. 94, no. 11, pp. 1015-1020, 2003.

[38] J. P. T. Higgins and S. G. Thompson, "Quantifying heterogeneity in a meta-analysis," Statistics in Medicine, vol. 21, no. 11, pp. 1539-1558, 2002.

[39] Z. Xiao, C. Wang, R. Zhou et al., "Can Aidi injection improve overall survival in patients with non-small cell lung cancer? A systematic review and meta-analysis of 25 randomized controlled trials," Complementary Therapies in Medicine, vol. 37, pp. 50-60, 2018.

[40] D. Mi, W. Ren, and K. Yang, “Adoptive immunotherapy with interleukin-2 \& induced killer cells in non-small cell lung cancer: a systematic review \& meta-analysis," Indian Journal of Medical Research, vol. 143, no. 7, pp. 1-10, 2016.

[41] R. Chen, X. Deng, H. C. Wu et al., "Combined immunotherapy with dendritic cells and cytokine-induced killer cells for malignant tumors: a systematic review and meta-analysis," International Immunopharmacology, vol. 22, no. 2, pp. 451-464, 2014.

[42] S. Li and J. Wang, "Curative effect of DC/CIK plus GP scheme in elderly patients with advanced non-small cell lung cancer. Medicine," Philosophy, vol. 36, pp. 32-35, 2015.

[43] C. Zheng, G. Yu, H. Wang et al., "Meta-analysis of chemotherapy and dendritic cells with cytokine-induced killer cells in the treatment of non-small-cell lung cancer," International Journal of Clinical and Experimental Medicine, vol. 8, no. 8, pp. 14527-14537, 2015. 
[44] J. Chen, Meta-analysis of DC-CIK treatment combined with chemotherapy for advanced non-small cell lung cancer [M.S. thesis], Shenyang: China Medical University, Shenyang, China, 2013.

[45] W. Reng, Biological immune therapy for non-small cell lung cancer: a systematic review and meta-analysis [M.S. thesis], Lanzhou: Lanzhou University, Lanzhou, China, 2014.

[46] Y. Xu, D. Xu, N. Zhang, F. Chen, and L. Junquan, “Observation of chemotherapy combined with cytokine-induced killer cells and dendritic cells in patients with the advanced non-small cell lung cancer," The Practical Journal of Cancer, vol. 25, pp. 163166, 2010.

[47] C. H. Sheng, F. Bao, and S. Xu, "Clinical research on chemotherapy combined with dendritic cell-cytokine induced killer cells for non-small cell lung cancer," Journal of Practical Oncology, vol. 26, pp. 503-506, 2011.

[48] J. Yuan, D. Peng, and J. Li, "Clinical effects of administering dendritic cells and cytokine induced killer cells combined with chemotherapy in the treatment of advanced non- small cell lung cancer," Journal of Clinical Pulmonary Medicine, vol. 16, pp. 1910-1911, 2011.

[49] J. He, J. Li, and M. Mo, "Immediate clinical effects of administering dendritic cells and cytokine induced killer cells combined with chemotherapy in the treatment of advanced non-small cell lung cancer," Medical Innovation of China, vol. 9, pp. 4-5, 2012.

[50] D. Peng, J. Li, J. H. Yuan et al., "Efficacy and safety of autologous DC and CIK cells combined pemetrexed in the treatment of elderly patients with non-small cell lung cancer," Chinese Journal of Immunology, vol. 648-51, no. 56, p. 28, 2012.

[51] S. B. Shi, T. H. Ma, C. H. Li, and X. Y. Tang, "Effect of maintenance therapy with dendritic cells: cytokine-induced killer cells in patients with advanced non-small cell lung cancer," Tumori, vol. 98, no. 3, pp. 314-319, 2012.

[52] L. Zhao, H. Wang, J. Zhao, and D. Zhang, "Clinical study of DC-CIK in combination with chemotherapy for elderly patients with advanced non-small cell lung cancer," Acta Academiae Medicinae Xuzhou, vol. 33, pp. 880-883, 2013.

[53] Y. Zhu, K. Du, D. Sun, S. Zhao, and Y. Min, "Chemotherapy combined with DCCIK for patients with advanced non-small cell lung cancer: a clinical study," The Journal of Practical Medicine, vol. 29, pp. 3180-3182, 2013.

[54] W. Han, H. Li, F. Gu, Z. Zhu, and D. Du, "Efficacy of DC-CIK cells combined with concurrent chemotherapy in the elderly with locally advanced non-small cell lung cancer. Jiangsu medical," Journal, vol. 40, pp. 1528-1530, 2014.

[55] B. Niu, L. Cui, S. Wang et al., "Clinical study of DC-CIK combined with chemotherapy in the treatment of stage III/IV lung adenocarcinoma," Chinese Journal of Clinical Researh, vol. 27, pp. 1487-1489, 2014.

[56] M. Zhang, T. Yang, Y. Shi et al., "Efficacy of DCs-CIK immunotherapy combined with chemotherapy in patients with advanced non-small cell lung cancer," Tumor, vol. 34, pp. 361-365, 2014.

[57] C. Cheng, "Analysis of efficacy of chemotherapy combined with DC-CIK regimen for NSCLC," The Practical Journal of Cancer, vol. 30, pp. 759-761, 2015.

[58] Y. Qu, G. Li, L. Xu, Y. Song, and H. Mu, "Clinical effect of DC-CIK combined with chemotherapy in treatment of patients with middle-advanced non-small cell lung cancer,"
Medical \& Pharmaceutical Journal of Chinese People's Liberation Army, vol. 27, pp. 72-76, 2015.

[59] Y. Wang, "Therapeutic effect of cellular immunotherapy with systemic chemotherapy for advanced lung cancer," China Practical Medical, vol. 10, pp. 149-150, 2015.

[60] H. Xu, "Clinical study of DC-CIK combined with TP chemotherapy for patients with lung adenocarcinoma," Journal of Clinical Emergency Call, vol. 16, pp. 625-628, 2015.

[61] L. Yang, Z. Hong, Q. Yu, L. Tang, and G. Li, "DCs-CIK immunotherapy combined with chemotherapy for patients with advanced non-small cell lung cancer," Progress in Modern Biomedicine, vol. 15, pp. 6146-6149, 2015.

[62] H. Zhao and Y. Jia, "Effect of DC-CIK immune therapy combined with conventional chemotherapy on serum indexes and peripheral blood immune function index of non small cell lung cancer patients," Journal of Hainan Medical University, vol. 21, pp. 967-970, 2015.

[63] Q. Dong, X. Pan, J. Ma, Z. Nan, Y. Li, and W. He, "The efficacy of Dc-Cik cell immunotherapy combined with PC chemotherapy in patients with advanced lung adenocarcinoma," Chinese Journal of Gerontology, vol. 36, pp. 34683470, 2016.

[64] Z. Dong, "Efficacy and safety of DC-CIK with chemotherapy in the treatment of advanced non small cell lung cancer," Medical Information, vol. 29, pp. 265-266, 2016.

[65] M. Wu, S. Wei, and X. Wang, "Short term efficacy of DC-CIK cells combined with chemotherapy in the treatment of non-small cell lung cancer," Contemporary Medicine, vol. 22, pp. 11-13, 2016.

[66] J. Yang, G. Gu, X. Wang, X. Li, Y. Zhan, and C. Liu, "Clinical effectiveness of autologous tumor antigen-pulsed dendritic cell-cytokine induced killer cells combined with chemotherapy in treatment of advanced lung adenocarcinoma," Chinese Journal of Cancer Biotherapy, vol. 23, pp. 83-88, 2016.

[67] Y. Yang, Y. Fang, Z. Ni, and L. Zhang, "Effect of chemotherapy combined with DC-CIK on the tolerance and living quality of elderly patients with non-small cell lung cancer," Chinese Community Doctors, vol. 32, pp. 26-27, 2016.

[68] C. Zhang, "Efficacy of DC-CIK cell combined with chemotherapy in patients with advanced non-small cell lung cancer," Women's Health Research, vol. 159, no. 68, 2016.

[69] Z. Zhang, Z. Wang, Y. Zhang, X. Wang, S. Zheng, and L. He, "Effects of DC,CIK combined with conventional chemotherapy on prolonging survival, improving quality of life of patients with advanced NSCLC," Chinese Journal of Medical Guide, vol. 18, pp. 130-132, 2016.

[70] I. R. Mackay, M. D. Goodyear, C. Riglar et al., "Effect on immunologic and other indices of adjuvant cytotoxic chemotherapy including melphalan in breast cancer," Cancer, vol. 53, no. 12, pp. 2619-2627, 1984.

[71] A. W. Tong, B. Seamour, J. M. Lawson et al., "Cellular immune profile of patients with advanced cancer before and after taxane treatment," American Journal of Clinical Oncology, vol. 23, no. 5, pp. 463-472, 2000.

[72] T. A. Steele, "Chemotherapy-induced immunosuppression and reconstitution of immune function," Leukemia Research, vol. 26, no. 4, pp. 411-414, 2002.

[73] Y. Mu, C. H. Zhou, S. F. Chen et al., "Effectiveness and safety of chemotherapy combined with cytokine-induced killer cell/dendritic cell-cytokine-induced killer cell therapy 
for treatment of gastric cancer in China: a systematic review and meta-analysis," Cytotherapy, vol. 18, no. 9, pp. 11621177, 2016.

[74] D. Shen, Z. H. Liu, J. N. Xu et al., "Efficacy of adoptive cellular therapy in patients with gastric cancer: a meta-analysis," Immunotherapy, vol. 8, no. 8, pp. 971-981, 2016.

[75] Y. Su, Y. Yang, Y. Ma et al., "The efficacy and safety of dendritic cells co-cultured with cytokine-induced killer cell therapy in combination with TACE-predominant minimallyinvasive treatment for hepatocellular carcinoma: a metaanalysis," Clinical Laboratory, vol. 62, no. 4, pp. 599-608, 2016.

[76] F. S. Wang, M. X. Liu, B. Zhang et al., “Antitumor activities of human autologous cytokine-induced killer (CIK) cells against hepatocellular carcinoma cells in vitro and in vivo," World Journal of Gastroenterology, vol. 8, no. 3, pp. 464-468, 2002.

[77] P. Wang, J. P. Yu, S. Y. Gao et al., "Experimental study on the treatment of intracerebral glioma xenograft with human cytokine-induced killer cells," Cellular Immunology, vol. 253, no. $1-2$, pp. 59-65, 2008.

[78] Q. J. Wang, H. Wang, K. Pan et al., "Comparative study on anti-tumor immune response of autologous cytokineinduced killer (CIK) cells, dendritic cells-CIK (DC-CIK), and semi-allogeneic DC-CIK," Chinese Journal of Cancer, vol. 29, no. 7, pp. 641-648, 2010.

[79] A. Marten, S. Renoth, M. von Lilienfeld-Toal et al., "Enhanced lytic activity of cytokine-induced killer cells against multiple myeloma cells after co-culture with idiotype-pulsed dendritic cells," Haematologica, vol. 86, no. 10, pp. 1029-1037, 2001. 


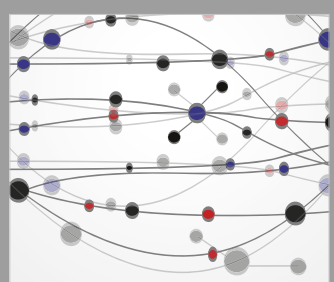

The Scientific World Journal
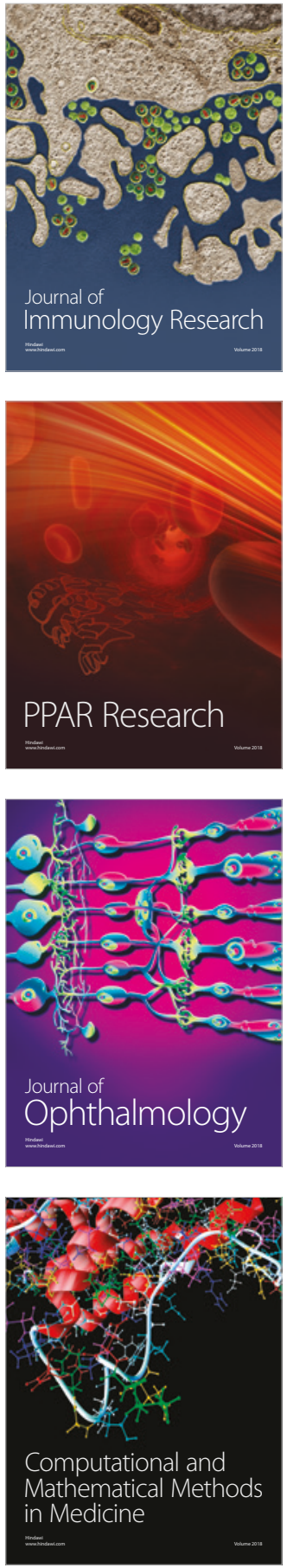

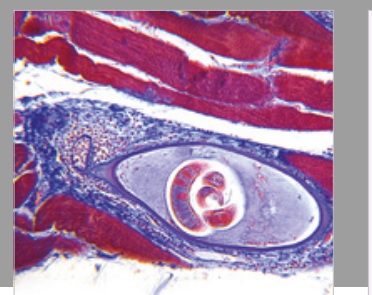

Gastroenterology Research and Practice

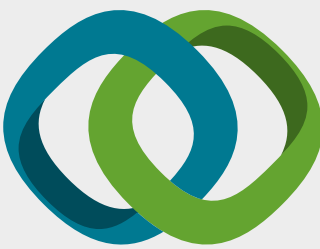

\section{Hindawi}

Submit your manuscripts at

www.hindawi.com
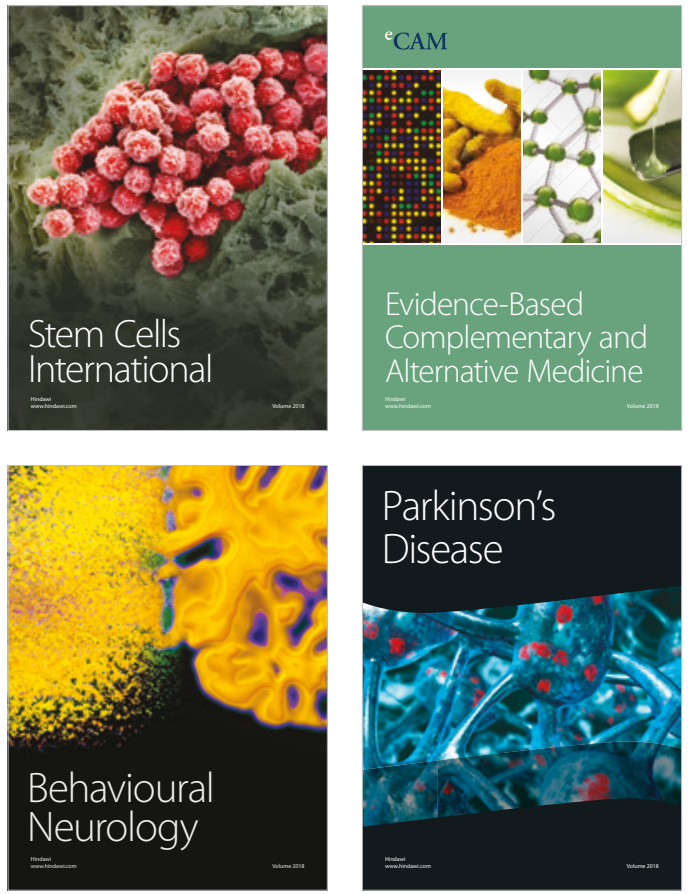

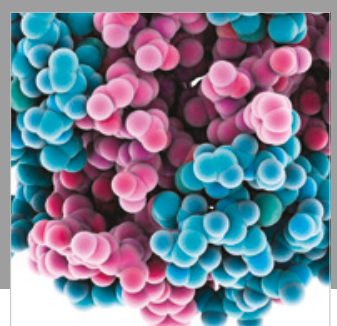

ournal of

Diabetes Research

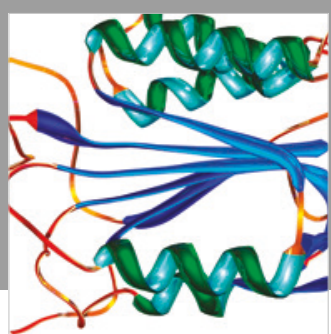

Disease Markers
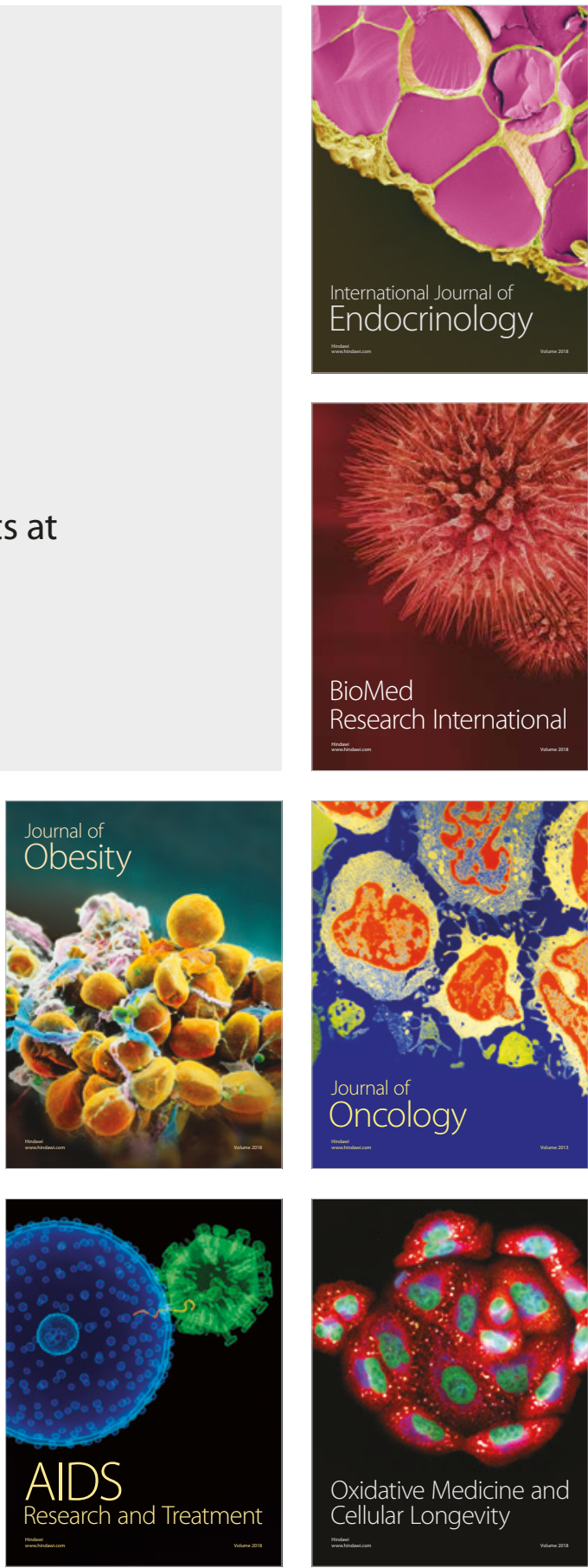